\title{
INTERACTUANDO DESDE EL ESTILO. VARIACIONES EN LA CIRCULACIÓN ESPACIAL Y TEMPORAL DEL ESTILO ALFARERO YAVI
}

\author{
Florencia Avila ${ }^{1}$
}

\section{* Introducción}

\begin{abstract}
Resumen
Se analizan los materiales alfareros de estilo yavi provenientes de distintos sectores de la provincia de Jujuy (Argentina). Nuestro objetivo inmediato es mostrar la variación espacial y temporal de este estilo en sectores lindantes a los de su supuesto origen. Las evidencias que empleamos son piezas cerámicas completas correspondientes a esta entidad que se encuentran distribuidas en diversas colecciones de instituciones y museos de Argentina. Como fin último, buscamos reflexionar sobre la dinámica de las interacciones sociales que generaron el traslado de materiales alfareros tanto a distintos lugares como en distintas épocas.
\end{abstract}

Palabras claves: estilo yavi - alfarería - circulación interacciones sociales.

\begin{abstract}
Our analysis of yavi style ceramics from different sectors of the Province of Jujuy (Argentina) aims to show this style's spatial and temporal variability in areas surrounding its supposed place of origin. Evidence provided by Yavi vessels kept in different argentinian collections finally leads us to discuss the dynamics of social interaction involved in the circulation of ceramics in different places and periods.
\end{abstract}

Key words: yavi style - pottery - circulation - social interaction. Recibido: noviembre 2007. Aceptado: julio 2008.
El dinamismo de las interacciones sociales que se sucedieron en la subárea circumpuneña (suroeste de Bolivia, II región de Chile y Noroeste Argentino) y sus cambios a través del tiempo, han sido objeto de múltiples investigaciones y discusiones en ámbitos de diversas disciplinas. Desde la arqueología los estudios han combinado evidencias materiales, etnográficas y etnohistóricas con el fin de discutir dichos procesos diacrónicamente. Dentro de esta línea de investigación, abordaremos el estudio de las interacciones sociales en esta región desde un aspecto de su materialidad, el estilo alfarero yavi ${ }^{2}$, preguntándonos por el rol de su circulación en la construcción y constitución de las relaciones sociales durante el período comprendido entre los siglos XI y XVI.

¿Qué podemos decir de dicho estilo alfarero? Tradicionalmente, la "entidad yavi" se asoció a un extenso lapso cronológico (500 DC hasta el contacto hispano-indígena), siendo su principal área de dispersión, y posiblemente de origen, el norte y el este de la Puna de Jujuy y la cuenca del río Grande de San Juan (región de Tupiza y serranías chichas en el sur de Bolivia) (Krapovickas y Aleksandrowiscz 1990). Pero materiales atribuidos a esta entidad han sido encontrados a ambos lados de los Andes en contextos de diversa cronología (Avila 2005). Esta amplia distribución nos planteó interrogantes sobre los

\footnotetext{
${ }^{1}$ CONICET. Instituto Nacional de Antropología y Pensamiento Latinoamericano, 3 de Febrero 1378. Capital Federal, CP: 142 8, ARGENTINA. Email: florenciaavila@gmail.com

${ }^{2}$ Denominado en minúscula para diferenciarlo de la región de Yavi.
} 
mecanismos que pueden haber sido responsables de su traslado a diferentes lugares en distintas épocas y sus implicancias para la comprensión de los procesos de interacción interregional. En este marco cabe preguntarnos ide qué modo se puede generar un aporte a la comprensión de la dinámica de las interacciones sociales a través de la cultura material planteando un análisis desde el estilo?

Para esto necesitábamos especificar las variables estilísticas que entraban en juego al definir la unidad perceptiva del estilo yavi. Con este propósito realizamos una sistematización de aspectos compositivos (morfológicos, cromáticos y pictográficos) de distintos materiales alfareros con la idea de reconocer las variables plásticas que lo identifican (Avila 2006, 2008). De esta sistematización nació el objetivo central de este trabajo: evaluar los contextos y los modos de circulación de dicho estilo, para identificar patrones en su distribución espacial y temporal. Si tomamos a las manifestaciones plásticas como significantes que cobran sentido en un entramado significativo que involucran objetos, prácticas sociales, esferas sociales, momentos particulares y espacios definidos, podemos postular que las distintas vías de circulación del repertorio yavi en el espacio y el tiempo guardan estrecha vinculación con nuevas construcciones de contextos y relaciones sociales, tanto a escala local, regional como suprarregional.

\section{- El “estilo yavi” en las investigaciones ACTUALES}

El proceso de identificación y construcción del repertorio iconográfico yavi en las investigaciones arqueológicas es sumamente complejo, al igual que lo sucedido con el estudio de otras manifestaciones plásticas en la arqueología. Sus conocimientos iniciales como una manifestación independiente 3 fueron desarrollados por Krapovickas y su equipo recién a partir de 1960, a partir de trabajos realizados en el sitio Yavi Chico y en áreas cercanas al río Grande de San Juan (Krapovickas

3 Independientes de "lo omaguaca", "lo calchaquí" o "lo puneño".
1965, 1973, 1975, 1977). Su tipificación estuvo dada por dos variables: el color y el antiplástico de sus piezas cerámicas y la circunscripción de estos materiales a los valles de los afluentes puneños del río Pilcomayo (río Grande de San Juan, arroyos Yavi y Yavi Chico) (Figura 1). A partir de ese momento y luego de sucesivos trabajos en la región puneña, Krapovickas realizó una sistematización tipológica teniendo como fin la delimitación categórica de la "cultura yavi" 4 , siendo la cerámica la base para la determinación de esta entidad.

$\mathrm{Al}$ seguir con los trabajos en el área de Yavi y en la cuenca del río Grande de San Juan, Krapovickas llegó a vincular esta zona, tanto geográfica como culturalmente, con la región de Tupiza. A partir de la "continuidad natural" que las relacionaba -ambas circunscritas dentro de los afluentes del Pilcomayo - se asumió una "continuidad cultural" entre las mismas (Krapovickas 1973, 1984, 1994). Se creó entonces un bloque de sitios en la Puna argentina que en función de un estilo alfarero se entendían como "propios" de la cultura yavi ${ }^{5}$, la que se extendía desde los valles de Tupiza (Krapovickas y Aleksandrowiscz 1990) (Figura 2). Por otro lado, en Bolivia, las investigaciones hablaban de un estilo "chicha" muy similar al yavi, que se encontraba distribuido en los valles de Tupiza y en la cuenca del río Grande de San Juan o San Juan del Oro (Ibarra Grasso 1957; Ibarra Grasso y Querejazu 1986; Raffino et al. 1986), el cual será luego denominado estilo "yavi chicha" (Angelo 1999). Ahora bien, a las publicaciones de Krapovickas se sumaron distintos estudios que reconocían "piezas yavi” en regiones alejadas a las del supuesto centro. Uno de los primeros fue el de Tarragó (1968, 1989), que señalaba estas piezas en tumbas en San Pedro de Atacama (Catarpe, Solcor, Vilama). Años más tarde, Pérez Gollán (1973: 673) propuso que uno de los estilos característicos de la Quebrada de Humahuaca en el período de Desarrollos Regionales (Tilcara Negro

\footnotetext{
4 Para ver cómo se desarrolló la construcción de esta categoría en el tiempo, ver Avila (2005).

5 Entre ellos podemos mencionar Yavi Chico, Cerro Colorado, Pueblo Viejo de La Quiaca, Chocoite, Pozuelos, Yoscaba, Calahoyo, Pucapampa, Peña, Pampa Grande y Pueblo Viejo.
} 


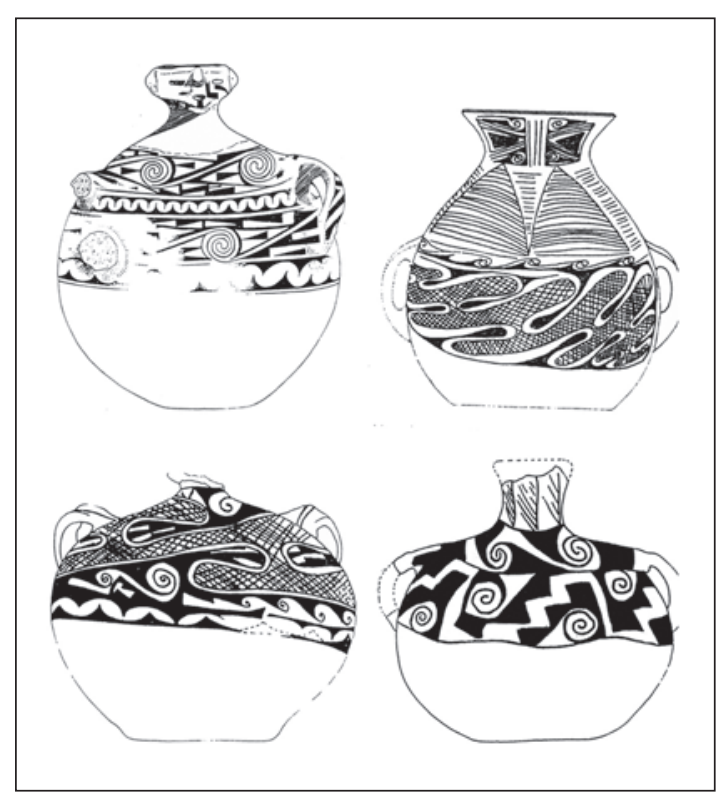

Figura 1. Piezas alfareras publicadas por Krapovickas y Aleksandrowicz (1990). sobre Rojo, que él denominara Purmamarca Línea Fina), no era originario de esa región, sino que era producto de la "influencia de la alfarería yavi sobre el tipo ya existente".

Estos argumentos que se sucederán harán de la "cultura yavi" un paquete de rasgos. Y al demostrar su presencia en contextos alóctonos, reforzarán la hipótesis de un territorio étnico y cultural en la Puna. La entidad estilística yavi tuvo un lapso temporal concreto y un espacio geográfico demarcado, este último relacionado con la región de Tupiza en Bolivia. La imagen que se construía detrás del estilo era la de una sociedad fuertemente estructurada, capaz de hacer llegar su cultura material y sus representaciones más allá de sus límites territoriales, una sociedad que no sólo se mantuvo con una fuerte hegemonía por más de 400 años, sino que también le hizo frente al dominio incaico, "negociando" con ellos.

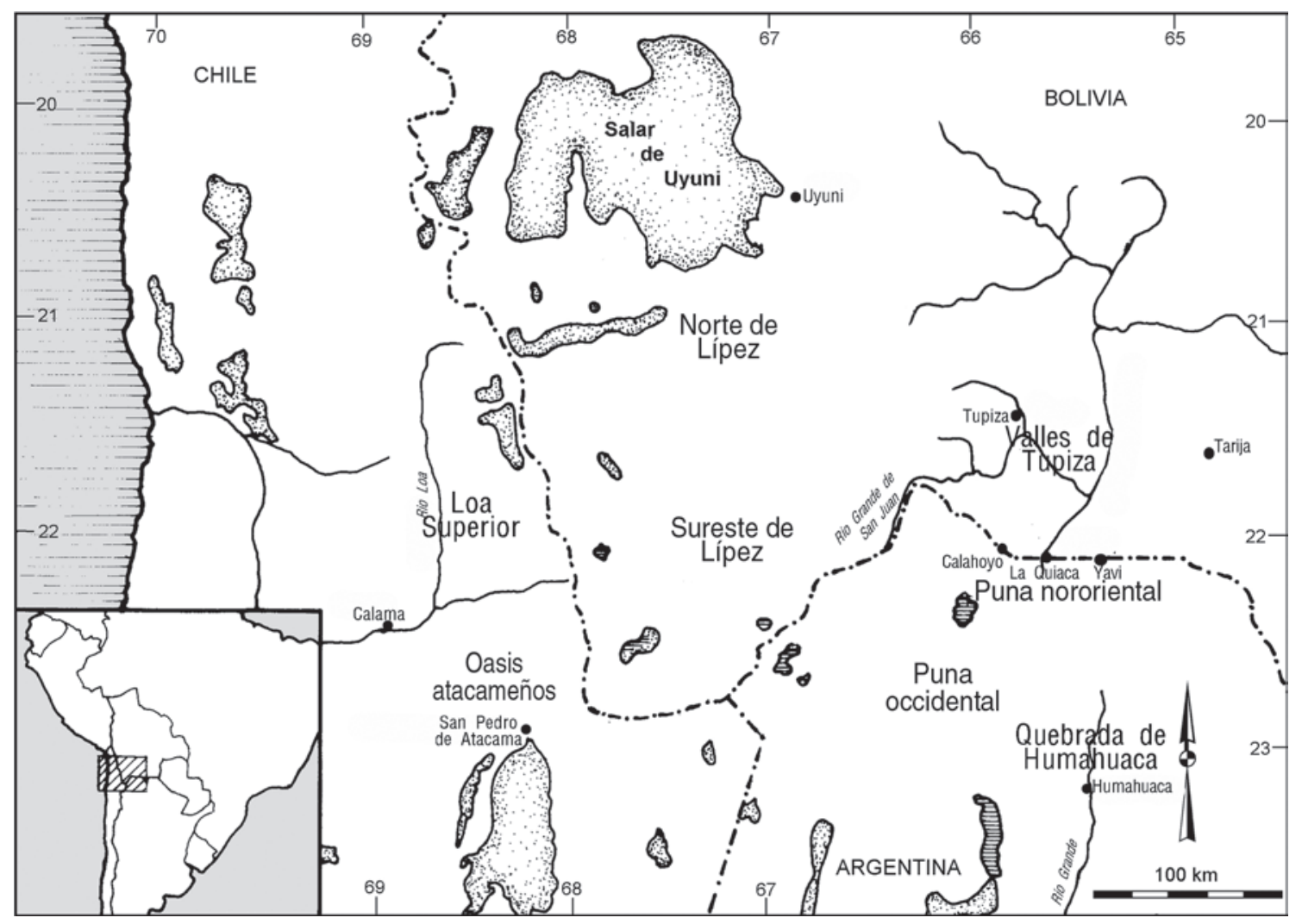

Figura 2. Regiones y localidades mencionadas en el texto. 
Si bien en la actualidad se han desarrollado distintas discusiones sobre la dinámica social en los Andes circumpuneños, los estilos plásticos siguen operando como nucleadores sociales emblemáticos. En este sentido, son extensas las publicaciones que presentan hoy en día evidencias de diversos materiales "yavi" (denominándolos "yavi”, "chicha" o "yavi chicha") en distintos sectores lindantes a la provincia Sud Chichas o más lejos aún.

En Bolivia las referencias provienen de diversos lugares. ${ }^{6}$ Entre ellos podemos mencionar el valle de Cinti en el suroeste del departamento de Chuquisaca (Rivera 1998 Ms, 2003, 2006), los valles bajos de Tarija (Von Rosen 1957; Arellano 1984; Raffino et al. 1986; Ventura 2001; Rendón 2004) y el Altiplano de Lípez (Nielsen 1998; Nielsen et al. 2000).

En la región del desierto atacameño (II región de Chile), los hallazgos dan cuenta de una amplia variabilidad. En el Museo Arqueológico de San Pedro de Atacama se encuentran aproximadamente 35 piezas alfareras yavi (denominadas yavi chicha) provenientes tanto de contextos funerarios como domésticos (Tarragó 1968, 1989; Fernández 1978; Martínez 1992, 1995; Stovel 2002; Uribe 2004a). El rango cronológico al que se las adscribe va desde el período Intermedio Tardío (1000-1450 DC) al Inca (1450-1536 DC), en asociación con estilos alfareros locales como Dupont, Gris Pulido, Rojo Violáceo y Solor (Stovel 2002; Uribe 2004a). Para el período Inca se plantea a su vez una mayor profusión del estilo a nivel regional, pero fusionado con elementos incaicos (Stovel 2002).

Procesos similares ocurren a lo largo de la cuenca del río Loa, como es el caso de las evidencias halladas en Caspana (Alliende 1981; Uribe 1997, 2004a; Adán y Uribe 2005), en Quillagua (Agüero et al. 1997), en Turi (Rydén 1944) y en los caminos incaicos del Alto Loa (Uribe y Cabello 2005). Asimismo, se han registrado ejemplares alfareros en el Museo Regional de Atacama, en Copiapó (Cantarutti y Mera 2003 Ms),

\footnotetext{
${ }^{6}$ Cabe aclarar que la falta de publicaciones sistemáticas en esta región conlleva un desequilibrio en relación con el material hallado.
}

en el cementerio Alto del Carmen en la cuenca del río Huasco (Niemeyer 1988) y en el Museo de La Serena (P. González 1995), entre otros. Proponiendo no sólo la presencia efectiva del material, sino también su influencia en piezas locales, como lo expone la cerámica del sitio Estadio Fiscal de Ovalle (en Coquimbo) denominada "Diaguita Mixta con influencia Yavi" y "Diaguita Mixta con influencia Yavi y Cusqueña" (Cantarutti y Mera 2000).

Los hallazgos de material de estilo yavi se han seguido multiplicando en alejados y diversos sectores. En las yungas orientales de Argentina se han registrado numerosos ejemplares: en el valle de Santa Victoria (Togo 1973; Ventura 2001), en los valles de San Andrés y Santa Cruz (al este de las serranías de Zenta) (Ventura 2001) y en la Sierra de Zenta (Nielsen 2003). En el sector sur de los valles orientales de Jujuy el material yavi se relaciona exclusivamente a momentos incaicos en asociación a alfarería inca local. Ejemplo de este tipo son los hallazgos efectuados en el sitio AP I Tiraxi, en la cuenca del río Tiraxi, y en el sitio Cucho de Ocloyas, en la cuenca del río Ocloyas (Garay de Fumagalli 1997, 2003).

En la Puna las evidencias de material se extienden desde los sitios Yoscaba, Pucara de Rinconada, río Grande de San Juan, hasta Pozuelos - sitios Pta. Rinconada, Mayu Punku, Puka Puka, Quebrada Farillon, Pueblo Viejo de Guayatayoc, Antiguyu-, Doncellas y Casabindo (Mamani 1998; Albeck 2001). En la Quebrada de Humahuaca la dispersión se extiende ampliamente, abarcando sitios como Los Amarillos, Pucara de Volcán, Pucara de Tilcara, La Isla, La Huerta, Angosto de Perchel y Yacoraite, entre otros (Cremonte 1992, 1994; Raffino y Palma 1993; Nielsen 2001; Rivolta 2005).

Hasta aquí hemos observado la gran dispersión temporal y espacial del estilo yavi, la que parece haberse duplicado en tiempos de la conquista incaica como comentamos anteriormente. Cabe aclarar que ésta no fue la única relación que se estableció entre el estilo yavi y el momento incaico, sino que se planteó una relación especial, en algunos lugares, entre el estilo 
yavi y los estilos cerámicos imperiales. El ejemplo más claro de esta hipótesis es el estilo Inka Paya. Este sería una derivación del yavi, tanto por las semejanzas en la técnica de realización como en los motivos icónicos (Krapovickas 1965, 1983). Calderari señala que: "El Casa Morada Policromo [o el Inka Paya] y el Yavi Policromo comparten varias características de producción: el pulimento, el color ante, el trazo fino, la pintura desleída" (1988:158). Es interesante que no sólo estas variables se compartan, sino que también aparezcan formas como escudillas con bordes inflexos o botellas subglobulares, configuraciones reversibles, así como también espacios de diagramación del diseño muy comunes en la alfarería yavi (Avila 2006). El estilo Inka Paya circuló aun dentro de un perímetro más amplio, llegando estas piezas no sólo a donde llegaba el estilo yavi, como a zonas de Bolivia (Raffino et al. 1986; Rivera 2003), Chile (Stovel 2002; Uribe 2004b) y Jujuy, sino también a sitios como Potrero Chaquiago (Calderari y Williams 1991; Lorandi et al. 1991), Potrero Payogasta (Williams y Cremonte 199293), La Paya (Calderari 1988; Calderari y Williams 1991), Fuerte Quemado y Ampajango II-Rosendo Cáceres (González y Tarragó 2005), Quebrada de Jujuil (Baldini y Albeck 1983), entre otros.

Como se observa, el estilo plástico yavi se distribuye en un amplio rango geográfico y temporal, asociado a contextos diversos. Su iconografía, o lo que se tomó como su configuración plástica representativa, se vio plasmada a lo largo del tiempo y del espacio, conllevando la idea de imposición de una "imagen" como medio de identificación o delimitación de una entidad que permitía dinámicas de interacciones sociales propias.

\section{* El estilo y su ANÁlisis}

En este marco indefectiblemente debemos preguntarnos ¿a qué llamamos "estilo alfarero yavi"? ¿Qué atributos son suficientes en cada caso para definir a algo como de estilo yavi? Sólo desde su aspecto metodológico y sin ahondar en la vasta discusión en torno al tema (Conkey y Hastorf 1990; Weissner 1990; Coote y Shelton 1992; Gell 1998), definiremos a un modo estilístico como una "forma de hacer" ciertos objetos en patrones reiterados generando una unidad perceptiva que es reconocida e identificada por un grupo de personas en un tiempo y en un espacio determinados. Es decir, una configuración particular de atributos formales que se relaciona directamente con una forma de construcción del saber intersubjetivo, provocando percepciones compartidas.

Si bien abogamos por esta concepción de estilo, con el fin de no generar ambigüedades a lo largo del artículo, debemos diferenciar conceptualmente entre el "componente" alfarero utilizado por las poblaciones de la cuenca del río Grande de San Juan y el "estilo" alfarero yavi. Siguiendo la terminología utilizada por otros investigadores en la subárea circumpuneña, utilizamos la categoría componente para referirnos al conjunto total de piezas cerámicas producidas y consumidas por determinadas poblaciones en un período particular (Uribe 1997; Rendón 2004; Nielsen 2007, entre otros). Por otro lado, aunque el concepto de estilo posee múltiples connotaciones e implicancias teóricas, baste aquí notar que empleamos este término para referirnos a un conjunto interrelacionado de atributos (morfológicos, cromáticos, pictóricos, tecnológicos) compartidos por una cantidad de artefactos. De esta forma, un estilo puede ser compartido por más de una población y convivir, a su vez, con otros materiales que no responden a los mismos cánones estilísticos dentro del repertorio alfarero (componente) utilizado por una población. Dado que el "estilo yavi" es el que - desde el trabajo de Krapovickas- se considera característico de las poblaciones de la Puna Nororiental y es el principal indicador utilizado al momento de plantear contactos entre ésta y otras regiones, se justifica centrar nuestra atención en los caracteres distintivos que lo identifican.

Con el propósito de identificar las variables plásticas que lo definen analizamos una muestra constituida por piezas enteras pertenecientes a colecciones museográficas de sitios de la Puna Nororiental y Occidental de Jujuy y de la Quebrada de Humahuaca (Tabla 1). Para ello tomamos en cuenta las variables más significativas señaladas en la bibliografía, y por 


\begin{tabular}{|c|c|c|c|c|}
\hline Región & Sitio & Museo & Piezas & Total \\
\hline \multirow{13}{*}{ 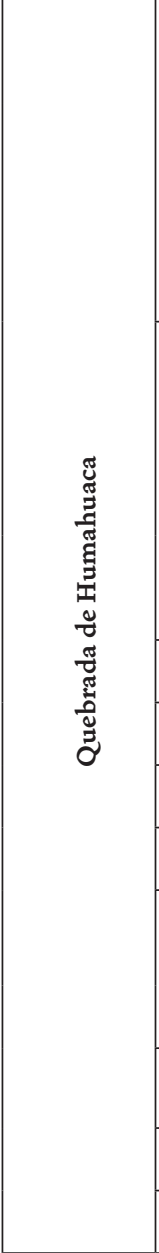 } & \multirow{2}{*}{ 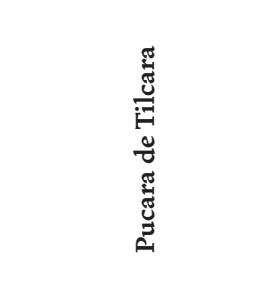 } & $\begin{array}{l}\text { ME (Museo Etnográfico, } \\
\text { Buenos Aires) }\end{array}$ & $\begin{array}{c}22948 ; 24383(37112) ; 35072 ; 35104 ; 35126 \\
35128 ; 4266 ; 4599 ; 4810 ; 8138\end{array}$ & \multirow{13}{*}{73} \\
\hline & & $\begin{array}{l}\text { IIT (Instituto } \\
\text { Interdisciplinario de } \\
\text { Tilcara) }\end{array}$ & $\begin{array}{c}2185(41-757) ; 2223(3412) ; 2286(27230) ; 2304 \\
(4701) ; 2321(27234) ; 2332(3756) ; 2353(4841) ; \\
2367(4367) ; 2548(4132) ; 2585(27229) ; 2595 \\
(3219)\end{array}$ & \\
\hline & $\underset{\widetilde{\pi}}{\frac{\pi}{\sqrt{n}}}$ & $\mathrm{ME}$ & $\begin{array}{c}2535(37100) ; 2606 ; 2652 ; 27232 ; 2750 \\
(08 / 251) ; 2758(08 / 259) ; 2772 ; 2813(37104) \\
3020 ; 35-366(37107) ; 36-198 ; 3675 ; 37-182 \\
37-237 ; 41-795 ; 41-800 ; 41-934\end{array}$ & \\
\hline & & IIT & $\begin{array}{c}2987(2945) ; 3106(2578) ; 3133(6129) ; 3430 \\
(35-313) ; 3439(2962)\end{array}$ & \\
\hline & Ciénaga Grande & IIT & $2822(65-477)$ & \\
\hline & Calle Sorpresa & IIT & 3479 & \\
\hline & Recinto XIX San José & IIT & 3871 & \\
\hline & Huacalera & IIT & $4301 ; 4309 ; 4310 ; 4320 ; 4322 ; 4335$ & \\
\hline & \multirow[t]{2}{*}{ Angosto Chico } & IIT & $\begin{array}{c}2506(39-371) ; 2834(38-119) ; 2835(38-330) \\
2845(38-293)\end{array}$ & \\
\hline & & $\mathrm{ME}$ & $38-329$ & \\
\hline & Volcán & IIT & $2702(40-221) ; 2727(40-196) ; 2767$ & \\
\hline & Peñas Blancas & $\mathrm{ME}$ & $26330 ; 26344 ; 26397 ; 26342$ & \\
\hline & Yacoraite & $\mathrm{ME}$ & $26219 ; 26285 ; 26287$ & \\
\hline \multirow{3}{*}{ 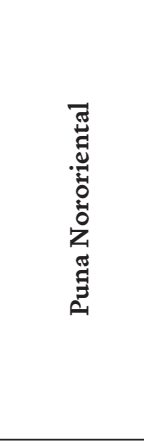 } & Yavi Chico & $\begin{array}{l}\text { Museo Arqueológico y } \\
\text { Colonial de Yavi Chico }\end{array}$ & $\begin{array}{l}1 ; 2 ; 3 ; 4 ; 5 ; 6 ; 7 ; 9 ; 10 ; 12 ; 13 ; 14 ; 15 ; 16 ; 17 ; 18 ; 19 \\
24 ; 25 ; 26 ; 27 ; 28 ; 29 ; 30 ; 31 ; 32 ; 33 ; 34 ; 37 ; 38 ; 39 \\
40 ; 41 ; 43 ; 44 ; 45 ; 42 ; 47 ; 48 ; 49 ; 50 ; 51 ; 52 ; 54 ; 55 \\
56,57 ; 58 ; 59 ; 60 ; 61 ; 124 ; 125 ; 126 ; 127 ; 128 ; 129 \\
\quad 130 ; 131 ; 132 ; 133 ; 134 ; 135 ; 136 ; 137 ; 138\end{array}$ & \multirow{3}{*}{111} \\
\hline & & $\begin{array}{l}\text { Museo Etnográfico “Mosoj } \\
\text { Nam” (La Quiaca) }\end{array}$ & $\begin{array}{c}4 ; 6 ; 19 ; 26 ; 27 ; 38 ; 45 ; 59 ; 60 ; 106 ; 108 ; 111 ; 112 \\
44 ; 43 ; 113 ; 14 ; 114 ; 31 ; 52 ; 35 ; 16 ; 29 ; 37 ; 2 ; 54 ; 47 \\
20 ; 12 ; 115\end{array}$ & \\
\hline & Calahoyo & $\begin{array}{l}\text { Museo Arqueológico } \\
\text { Provincial (San Salvador } \\
\text { de Jujuy) }\end{array}$ & $\begin{array}{c}117 ; 107 ; 106 ; 105 ; 104 ; 108 ; 109 ; 110 ; 111 ; 112 ; 114 ; \\
101 ; 115 ; 116 ; 103\end{array}$ & \\
\hline $\begin{array}{c}\text { Puna } \\
\text { Occidental }\end{array}$ & Doncellas y Queta & IIT & $\begin{array}{c}1657(42-2080) ; 1672(43-1126) ; 1673(42-107) ; \\
1800(43-1125) ; 1856(43-1130) ; 1859(43-1147) ; \\
1984(44-1415) ; 1991(18044) ; 2006(44-1534) ; \\
1819(44-991)\end{array}$ & 10 \\
\hline
\end{tabular}

Tabla 1. Muestra analizada. 
lo general popularmente usadas por otros investigadores, plausibles de ser reconocidas en piezas enteras (Krapovickas 1973, 1975; Krapovickas y Aleksandrowicz 1990). Estas fueron:

a) Tratamiento de superficie: tonalidad del color del engobe utilizado (morado, rojo, ante), diseño pictórico plasmado (motivos, configuraciones), color desleído del diseño, pulido de las piezas.

b) Morfología: formas características (botellas con asas asimétricas, cántaros de cuello abierto - baldes-, cantaritos con cuerpo bajo y cuello cilíndrico inflexo).

c) Pasta: variables macroscópicas, como el color anaranjado de la pasta o la presencia a simple vista de inclusiones blancas. Por trabajar con piezas enteras esta variable fue dejada de lado, 7 focalizándonos en las dos primeras.

Se realizó así una sistematización de las piezas alfareras (Avila 2006), tomando a cada una de ellas como unidad de análisis, dividiéndola en dos grandes bloques:

1) Sistematización del repertorio morfológico. Definiendo grupos formales, tipos morfológicos por la complejidad del perfil de la pieza y subtipos o variedades por particularidades específicas (tipo de borde, características de las asas, apéndices, etc.).

2) Sistematización estilística. Estableciendo campos de diseño estructurantes del espacio de cada pieza por la interrelación de dos variables interdependientes: el diseño cromático y el diseño pictórico. Registrando, en el primero de los casos, la variabilidad de color del conjunto (registrando piezas monocromas - de un color de fondo- y policromas -de más de un color

\footnotetext{
7 Entendemos que decisiones tecnológicas que afectan el desempeño de las piezas y el aspecto de sus pastas son parte integral de la definición de un estilo (Lechtman 1977). En este trabajo, sin embargo, no hemos tomado en consideración estas variables porque trabajamos con vasijas enteras, debiendo aceptar las limitaciones de observación y muestreo que éstas implican. No obstante, existen estudios detallados sobre la tecnología y pastas de materiales de estilo yavi (Cremonte 1994, 2005; Cremonte y Solís 1998).
}

de fondo) y, en el segundo, el repertorio de motivos, sus articulaciones particulares en un panel de representación (configuraciones) y las articulaciones entre los distintos paneles de una pieza que ofrecerían una forma particular de segmentar el espacio.

A partir de estos datos evaluamos las relaciones de interdependencia que se ponen en juego entre todos los atributos de la pieza, produciendo una identidad perceptiva (Figura 3 ). Cada pieza es un universo compositivo, una composición estilística que sólo cobra sentido como tal en su totalidad. Los motivos icónicos de una pieza alfarera, por ejemplo, no tienen sentido alguno si se ven de forma aislada. Cada uno de ellos toma relevancia y significación a partir de la disposición que arma en cada soporte, en los juegos de forma que establece. A su vez, los soportes no inscriben un mensaje uniforme, más bien éste es construido a partir del diálogo que se ejecuta entre los campos restantes, pudiendo establecer un valor significativo recién al leer el objeto en su totalidad. Es así como observamos que el estilo alfarero yavi tiene combinaciones pautadas de color, forma y pictografía, produciendo segmentaciones particulares de su espacio plástico (Avila 2006). ${ }^{8}$

\section{* Sus múltiples contextos}

Ahora bien, las manifestaciones plásticas no son entidades estáticas que se mantienen de forma homogénea en tiempo y espacio como un paquete de rasgos inamovible. Los estilos son entidades dinámicas, que cobran significación en distintas esferas de la práctica social y a partir de su interrelación en contextos particulares (Beaudry et al. 1991; Gell 1998; Lesure 2005). Dado que esta entidad fue asociada a un período tan extenso y evidencias de la misma se encuentran en distintos puntos de la subárea circumpuneña, nos preguntamos ipodemos identificar a partir del solo registro de piezas de colecciones museográficas variaciones estilísticas producto tal vez de variables diacrónicas

\footnotetext{
8 Para ver el proceso detallado del análisis iconográfico y morfológico del estilo yavi, ver Avila (2008).
} 
o espaciales? ¿Los juegos de percepción de las piezas cambian en el tiempo y dependen del contexto social en donde entran en acción?

\section{Variable temporal}

Si bien establecer una cronología precisa en conjuntos alfareros de colecciones museográficas es complicado dada la ausencia de contextos fechados de los materiales, podemos aproximarnos a un marco cronológico desde otras vías. En nuestro caso optamos por brindar una resolución temporal de grano grueso a partir de la asociación con contextos arqueológicos de cronología conocida. De este modo, distinguimos dos grupos estilísticos que se corresponderían con bloques temporales diferenciados. Al primero de ellos, denominado grupo estilístico calahoyo, lo hemos asociado a un momento temprano (500-900 DC), mientras que al segundo, denominado grupo estilístico yavi, a un momento tardío (900-1536 DC). En este último hay pequeñas variaciones que se exhiben en su interior que llevan a segmentarlo en dos subgrupos cronológicamente diferenciados. Por un lado, el subgrupo yavi temprano asociado a lo que en la Quebrada de Humahuaca se conoce como período Desarrollos Regionales I o Temprano (PDR I: 900-1250 DC) y, por el otro, el subgrupo yavi tardío-inca relacionado al período Desarrollos Regionales II o Tardío (PDR II) e Incaico (1250-1536 DC) (Nielsen 2001).

Esta división en dos subgrupos sólo fue aplicada para los materiales yavi provenientes de sitios de la Quebrada de Humahuaca, dado que es sólo allí donde podemos vincular ciertas variaciones en la composición plástica de las piezas con contextos bien documentados y datados.? Es por ello que empleamos el esquema cronológico vigente en esa región, que plantea la subdivisión del período Desarrollos Regionales ${ }^{10}$ en dos fases (I y II),

\footnotetext{
9 Tenemos en cuenta, igualmente, que las características particulares de estos materiales pueden relacionarse al contexto en el que se encontraron (enterratorios en la Quebrada), teniendo como hipótesis pendiente a contrastar si se presenta dicha variabilidad en contextos de la Puna Nororiental y valles de Tupiza.

10 También denominado Agroalfarero Tardío en el Noroeste Argentino (A. R. González 1963) e Intermedio Tardío en el norte de Chile (Schiappacasse et al.1989, entre otros).
}

relacionadas con sendos componentes alfareros (islaalfarcito y humahuaca) y que se encuentra respaldado por numerosas dataciones absolutas ( $\mathrm{C}^{14}$ y TL) y relativas (superposiciones estratigráficas, seriaciones tipológicas) (Nielsen 2007). Los momentos PDR II (1250-1430 DC) e Incaico (1430-1536 DC) han sido tomados como un bloque dado que, si bien en el momento incaico se incorporaron nuevos grupos alfareros, la producción y la circulación cerámica de momentos anteriores se mantuvo, marcando en muchos casos una larga continuidad, aunque no descartamos en un futuro la posibilidad de identificar variantes con implicaciones cronológicas.

A continuación caracterizaremos los materiales correspondientes a los tres momentos propuestos:

Grupo estilistico calahoyo. Momento Temprano (500-900 $D C$ ). Este grupo ha sido diferenciado por un repertorio morfológico e iconográfico específico que, a su vez, posee una relación particular con la segmentación de su espacio compositivo. Dentro del mismo hemos ubicado a los cantaritos con cuello abierto, variedad "baldecitos", a los que varios autores se han referido, por lo que existe cierta confusión en la literatura (Krapovickas 1977, 1994; Fernández 1978; Tarragó 1989; Stovel 2002, entre otros). Una de las primeras publicaciones que grafican estos materiales es la de Fernández para el sitio Calahoyo, asociándolos a una fase temprana y denominándolos "cerámica chicha" (Fernández 1978: Figs. 5-9). Ejemplares de las mismas características fueron relacionados por Tarragó a contextos del período Medio en San Pedro de Atacama, específicamente, a la fase IV o Quitor (400-700 DC) por su asociación a material del estilo San Pedro Negro Pulido (Tarragó 1989: 426, Figs. 55.5-7 y 22.1), los que también fueron publicados por Bravo (1991: 117) y Stovel (2002: 235). La situación se vio complejizada por hallazgos en los valles de Tarija, siendo asociados allí a la "cultura alfarera" del mismo nombre (Arellano 1984).

Ahora bien, distribuidos en los oasis de Atacama, en los valles de Tarija y en la Puna Occidental de Jujuy, siendo denominados "baldes chichas" (Tarragó 1989; 
Uribe 1997) o "cuencos tarija" (Arellano 1984; Stovel 2002), estas piezas se diferencian de las asociadas al estilo yavi. De hecho, Krapovickas (1994) plantea que estos no son como los baldes típicamente yavi, sino que pertenecen a otra variedad, pudiéndoselos asociar a una fase temprana dado que no aparecen en el sitio de Yavi Chico, ni en la Quebrada de Humahuaca.

En nuestro caso, se encuentran asociadas a escudillas troncocónicas simples con cuatro apéndices y a cuencos con asa lateral, no sólo por sus características morfológicas, sino también por sus características compositivas, formando en total un grupo de 21 piezas (Figura 4). Su diseño es monocromo (negro desleído sobre rojo o ante) y el 52\% posee diseño pictórico, utilizándose configuraciones en friso, formadas por motivos lineales de recorrido (Avila 2008) en la superficie externa de las escudillas y en el cuello de los cantaritos. Como se observa, se distinguen rápidamente del grupo estilístico yavi formando otro completamente diferente. Otras dos características que también las identifican son su pasta porosa y los apéndices en los labios de los cuencos y escudillas, variante no observada en las piezas del grupo estilístico yavi.

Creemos como Krapovickas (1994) que estos materiales podrían estar asociados a un momento más temprano, tanto por las asociaciones en San Pedro de Atacama como por su ausencia en el sitio Yavi Chico y en los sitios de Quebrada de Humahuaca, por lo cual los hemos integrado dentro del grupo estilístico calahoyo, denominado así para diferenciarlo estilística y temporalmente del grupo yavi.

Grupo estilístico yavi. Como ya dijimos, el estilo alfarero yavi tiene combinaciones pautadas de color, forma y pictografía que producen no sólo segmentaciones particulares de su espacio plástico, sino también operan como "particularidades pregnantes" que hacen su distinción en el contexto en donde se encuentren. Las mismas son: a) delimitación de campos de diseño por contraste de color; b) presencia de lecturas alternativas: frontal y continua; c) existencia de morfologías características por su frecuencia (p.e., botellas subglobulares con asas asimétricas, baldes, cántaros con cuerpo bajo y cuello cilíndrico inflexo, cántaros con base cónica, escudillas con borde inflexo); d) recurrencia de diseños pictóricos reversibles; e) composición cromática dividida en piezas monocromas y policromas, y f) presencia de alteraciones en las simetrías del diseño pictórico (ver Figura 3).

Yavi Temprano. Momento PDRI (900-1250 DC). Hemos incluido en este subgrupo a los materiales de las colecciones de los sitios de la Isla de Tilcara y Huacalera (Quebrada de Humahuaca), dado que ambos poseen materiales del componente Isla-Alfarcito asociado a fechados entre 900-1250 DC (Nielsen 2001). De este conjunto forman parte 28 piezas, cuya mayor frecuencia la presentan las escudillas hemisféricas, hemisféricas con inflexión pronunciada y asimétricas, así como también los cántaros de cuerpo bajo inflexos (Figura 5). De las mismas un alto porcentaje (54\%) presenta combinaciones cromáticas policromas, con gamas que van desde el negro desleído sobre morado y ante, negro desleído sobre rojo y ante al negro desleído sobre rojo. Por otro lado, aunque la presencia de diseño pictórico es recurrente ( $71 \%$ ), son pocas las configuraciones utilizadas, sólo en friso, axial, zigzag angular o reversible.

Hay dos particularidades que destacar. En primer lugar, los cantaritos con cuerpo bajo inflexo los observamos únicamente en este momento (Figura 5.1), estando ausentes con posterioridad a él. Presentan diseño cromático policromo y pictórico con configuraciones tipo reversibles o en friso, siendo además, por lo general, piezas pequeñas de no más de $150 \mathrm{~mm}$ de alto. En segundo lugar, si bien no olvidamos que nuestra muestra es sesgada, al observar en conjunto las piezas de este subgrupo podemos notar que la gran mayoría son pequeñas $(120 \mathrm{~mm}$ de altura media para los cántaros y las botellas, y $50 \mathrm{~mm}$ de altura media para las escudillas) (Figura 6). Existe aquí una correlación con los materiales de los grupos quebradeños isla-alfarcito, en los que predominan piezas pequeñas asociadas preferencialmente a contextos mortuorios o rituales (Nielsen 2001). 


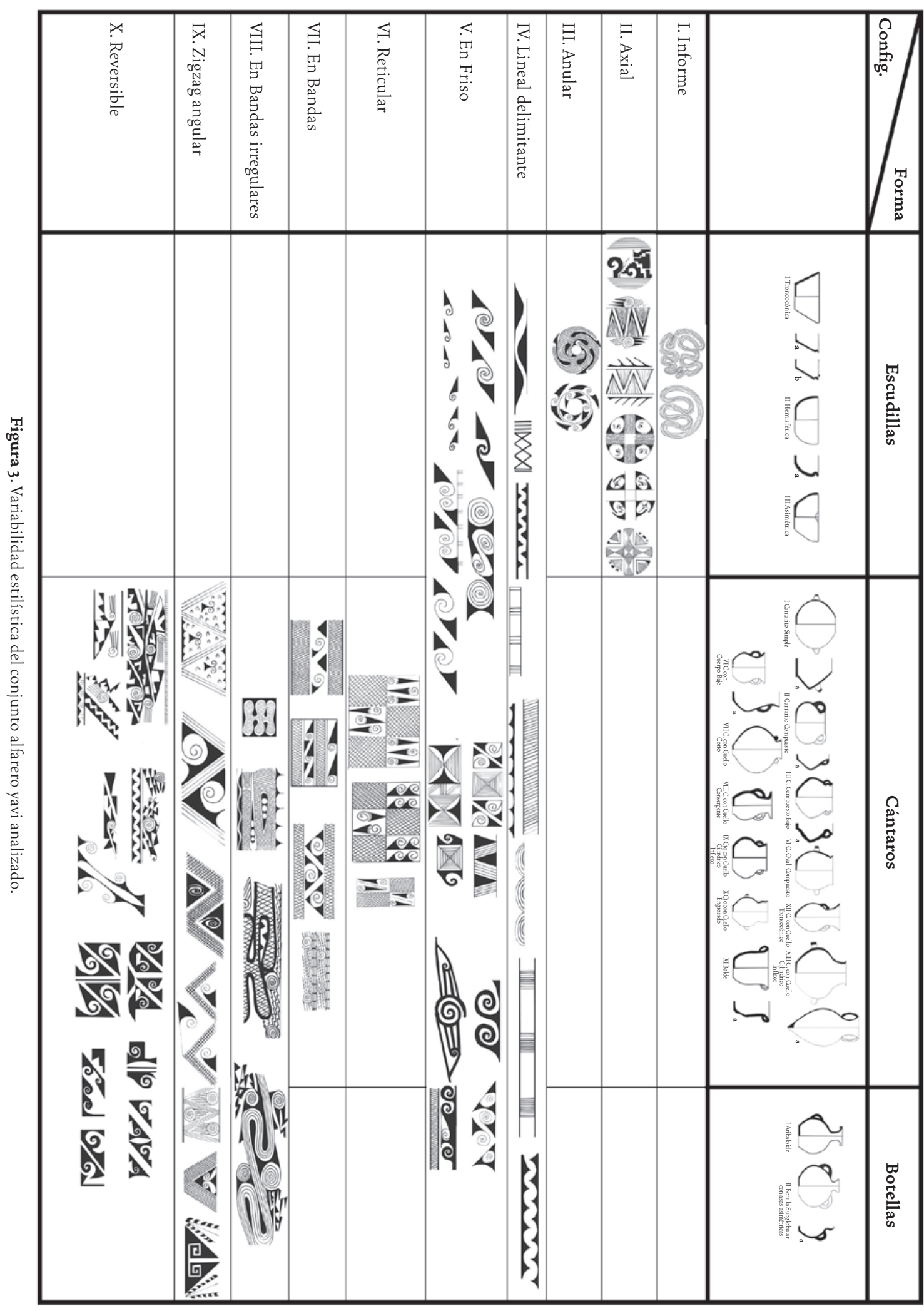




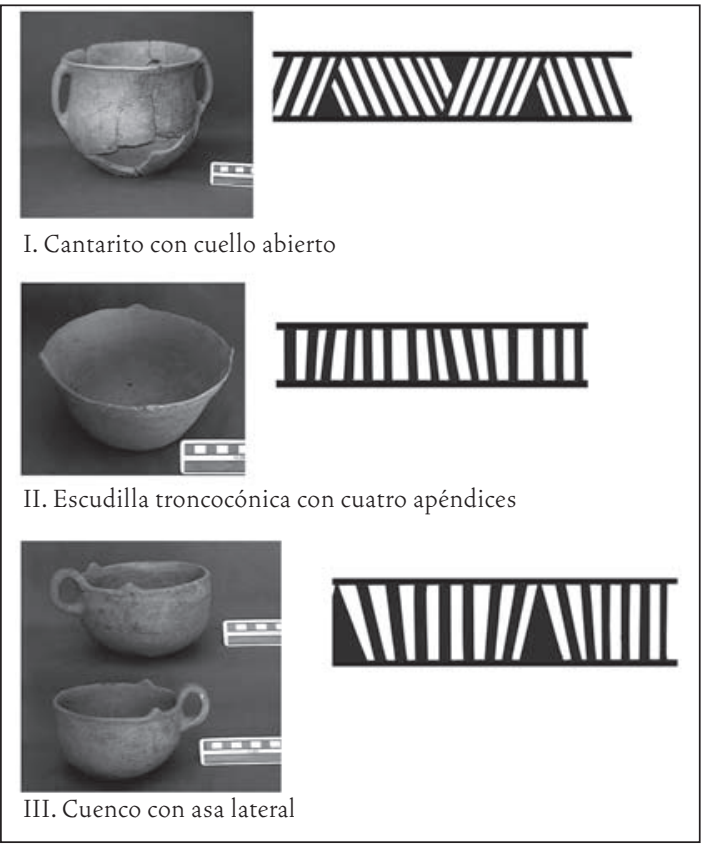

Figura 4. Grupo estilístico calahoyo.
Yavi Tardío-Inca. Momento PDR II e Inca (1250-1536 $D C)$. En este contexto hemos incluido las colecciones de los sitios quebradeños Pucara de Tilcara, Pucara de Volcán o Coiruro, Pucara de Yacoraite, Pucara de Peñas Blancas, Huella y Angosto Chico. Aunque en los primeros tres sitios mencionados se han encontrados rastros de ocupaciones del PDR I, estos son muy reducidos y espacialmente limitados, por lo que es razonable suponer que la mayoría de los materiales yavi provienen de contextos del PDR II e Inca que son los dominantes en ellos.

En rasgos generales, y en comparación con el momento anterior, de las 41 piezas analizadas sólo el 24\% posee un diseño policromo. En el diseño pictórico, presente en el $59 \%$ del total, las configuraciones utilizadas aumentan, incorporándose las reticulares, en bandas y en bandas irregulares (Figura 7 , Tabla 2 ).

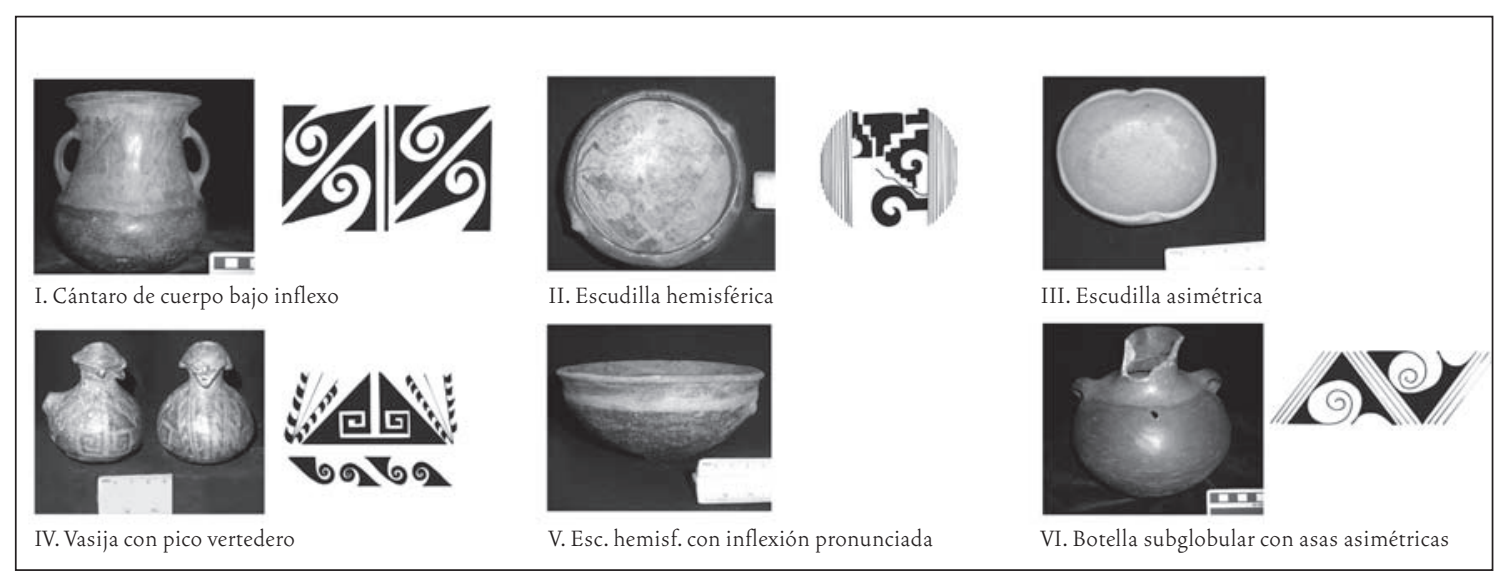

Figura 5. Grupo estilístico yavi. Subgrupo yavi temprano.

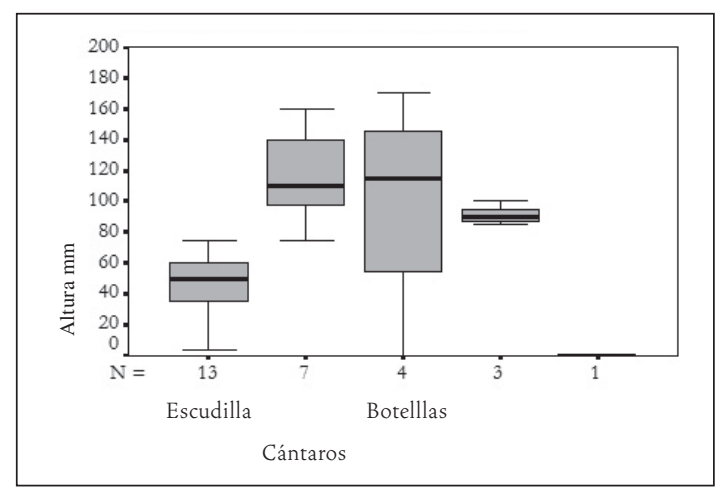

Figura 6. Altura media de las piezas del subgrupo yavi temprano.

También hay nuevos ejemplares. En primer lugar tenemos cántaros con cuerpo bajo angular y con cuello troncocónico, que se asemejan a los "pelikes" de la Quebrada de Humahuaca (Palma 1998), relacionados con la presencia incaica (Figura 7.1). ${ }^{11}$ Los mismos comparten un punto angular en el cuerpo, asas con apéndices, diseño cromático monocromo y diseño

\footnotetext{
11 Otro ejemplar relacionado a momentos incaicos es el aribaloide
IIT 2332 (3756) (Figura 7.3) proveniente del Pucara de Tilcara;

${ }^{11}$ Otro ejemplar relacionado a momentos incaicos es el aribaloide
IIT 2332 (3756) (Figura 7.3) proveniente del Pucara de Tilcara; podría corresponder al estilo Inka Paya o Casa Morada Policromo
(Calderari 1988). podría corresponder al estilo Inka Paya o Casa Morada Policromo
(Calderari 1988).
} 
pictórico con configuraciones del tipo reticular, en bandas o en bandas irregulares. ${ }^{12}$ En segundo lugar, si bien nos encontramos con la ausencia de ejemplares del tipo cantarito con cuerpo bajo, se encuentran presentes otros ejemplares (cantaritos con cuello cilíndrico inflexo) con combinaciones de diseños cromáticos y pictóricos similares (Figura 7.4).

Más allá de los casos puntuales, una de las particularidades del conjunto alfarero asociado al PDR II, que podría también deberse a variaciones diacrónicas, es el tamaño de las piezas (Figura 8). Los ejemplares poseen una mayor altura, diámetro y capacidad, particularidad semejante a las tendencias en la alfarería local. Uno de los fenómenos que se plantea para el siglo XIII en Quebrada de Humahuaca es la aparición de nuevas prácticas en áreas públicas, que conllevan cambios en los estilos alfareros pintados, que se relacionan con la preparación, distribución y consumo colectivo de alimentos y bebidas (Nielsen 2006). La construcción y transformación de nuevas prácticas sociales afecta a todas las materialidades de un grupo social. Estos cambios también se evidenciarían en la alfarería de estilo yavi, que se insertaría en nuevas prácticas de producción, consumo y circulación.

El estilo yavi en el tiempo. Hemos distinguido dos conjuntos estilísticos diferentes, el grupo estilístico calahoyo y el grupo estilístico yavi. El primero, asociado al período entre 500 y $900 \mathrm{DC}$ y, el segundo, a un lapso temporal más amplio que abarca desde ca. 900 a 1536 DC, y segmentado en dos subgrupos. Como se señaló, además de distinciones estrictamente plásticas, estos subgrupos difieren entre sí en la función y tamaño relativo de las vasijas. Dado que dicha subdivisión se planteó a base de asociaciones en contextos de la Quebrada de Humahuaca, donde los estilos locales contemporáneos (isla-alfarcito, humahuaca) experimentan un cambio análogo, surgen dos posibilidades interpretativas. La primera, atribuiría las diferencias a un cambio en la demanda

\footnotetext{
12 Los sitios en donde se hallaron estos materiales fueron Angosto Chico, Pucara de Volcán y Pucara de Tilcara (IIT 2506 (39-371), 2767; ME 22948, 38-329).
}

de las comunidades humahuaqueñas sobre la alfarería de estilo yavi, relacionada con procesos locales, sin implicar necesariamente que la cerámica yavi en la Puna Nororiental haya experimentado una transformación similar. En otras palabras, podría reflejar sólo una diferencia en lo que "circula" hacia o "se consume" en la Quebrada. La segunda, interpretaría estas diferencias como un cambio en el estilo yavi en su "territorio nuclear", que mostraría paralelismos con cambios ocurridos en Humahuaca y, tal vez, en otras regiones circumpuneñas que aparentemente sufrieron también importantes transformaciones en su cultura material alrededor del siglo XIII como resultado de procesos sociales operantes a una escala suprarregional. En apoyo de esta segunda interpretación, cabe recordar que el período Desarrollos Regionales o Intermedio Tardío ha sido subdividido en fases similares -que conllevan cambios en la alfarería - en otras regiones como San Pedro de Atacama (Tarragó 1989; Uribe 2002), el Loa Superior (Berenguer 2004) y Lípez (Nielsen 2002). Por cierto, la evaluación de estas alternativas y la consiguiente subdivisión del estilo yavi en unidades de significación cronológica requerirán el estudio y datación de contextos dentro de la propia región, tarea que se encuentra aún pendiente.

\section{Variable espacial}

Ahora bien, veamos cuál es la variabilidad que presenta este estilo a nivel espacial. Se tiende a pensar que en los lugares de "origen" de la producción alfarera se encuentran los mismos objetos que en los lugares a donde circula, salvo la cerámica tosca o piezas de gran tamaño que no podrían ser transportadas con facilidad. En este sentido, si tomamos como supuesto que el centro de origen es la región de la Puna Nororiental de Jujuy y sur de Bolivia, sería interesante pensar qué objetos están circulando y cuáles no. Segmentaremos el análisis del grupo estilístico yavi en tres regiones: Puna Nororiental, Puna Occidental y Quebrada de Humahuaca.

Región de la Puna Nororiental. De aquí han sido analizadas 93 piezas. En cuanto a su morfología, un $40 \%$ son escudillas, $37 \%$ cántaros, $19 \%$ botellas; respecto 


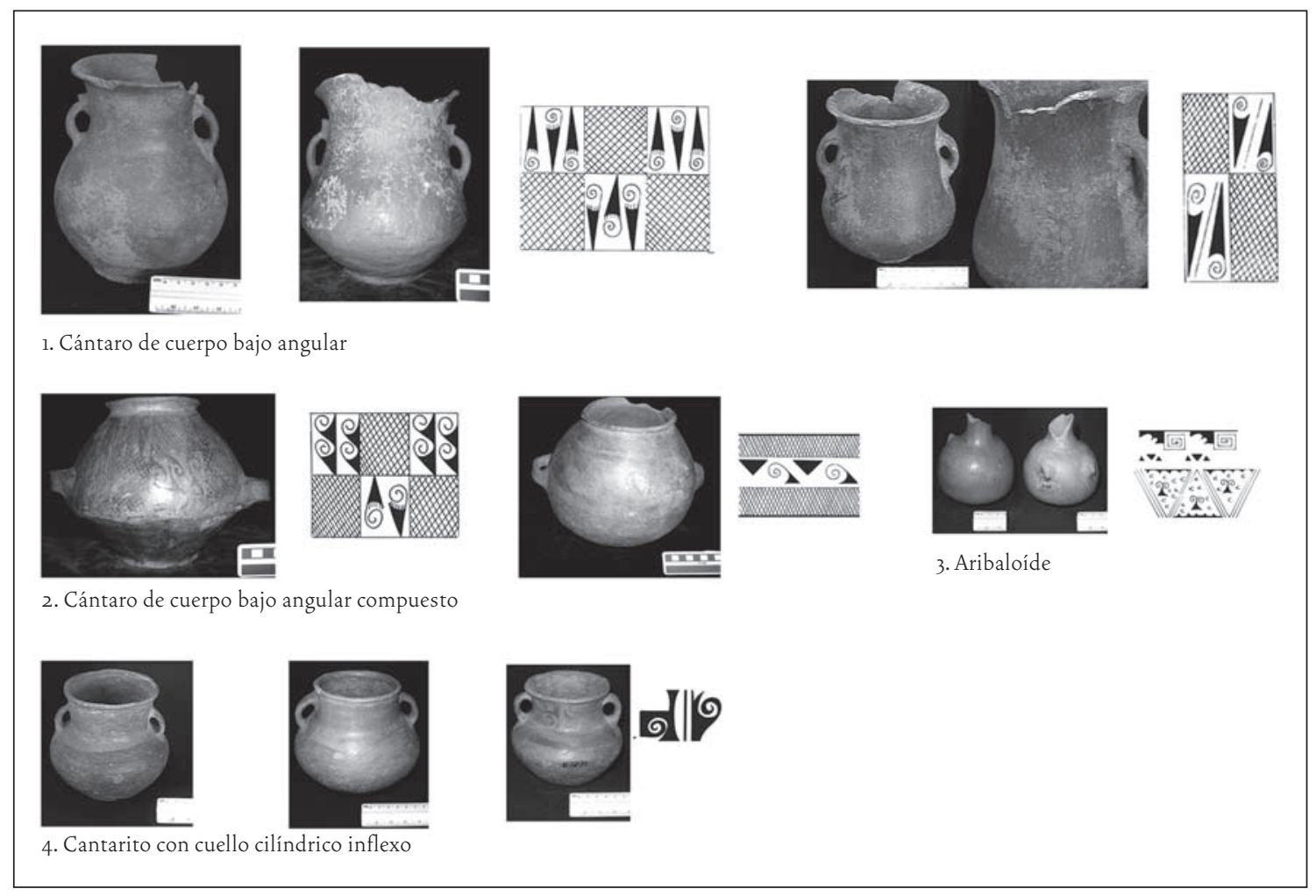

Figura 7. Grupo estilístico yavi. Subgrupo yavi tardío.

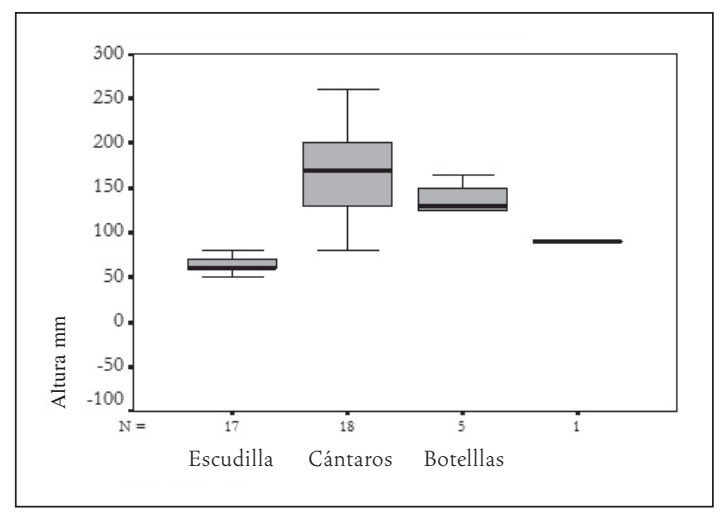

Figura 8. Altura media de las piezas del subgrupo yavi tardío.

a su composición plástica, el color es en su mayoría monocromo (73\%) y el diseño pictórico es escaso (34\%). De estos últimos las combinaciones más recurrentes son configuraciones en friso, reversibles y en bandas irregulares.

En comparación con otras regiones observamos, en primer lugar, la presencia de "baldes", tipo morfológico que ha sido uno de los elementos diagnósticos cruciales para definir este estilo. ${ }^{13}$ Estos ejemplares sólo han sido registrados en sitios de la Puna Nororiental, no así en la región de Quebrada de Humahuaca, oasis de Atacama o Puna Occidental (Krapovickas 1994). Una peculiaridad interesante es que muchos de ellos poseen un agujero en su base. Estos son uniformes y se presentan en vasijas que no parecen haber sido expuestas a una continua utilización. Krapovickas (1973) propone una interpretación de estos agujeros, relacionándolos con la práctica de "matar las vasijas", dado que, al producir ese orificio en su base, dejan de tener la "funcionalidad de contener" (Figura 9).

Un segundo aspecto a tener en cuenta es la presencia de piezas de grandes dimensiones con base cónica, ausentes en otros contextos. Dichas piezas han sido

\footnotetext{
${ }^{13}$ El término "balde" ha sido extraído de los trabajos de Krapovickas,
siendo este el primer autor en llamar así a estas piezas (Krapovickas

13 El término "balde" ha sido extraído de los trabajos de Krapovickas,
siendo este el primer autor en llamar así a estas piezas (Krapovickas 1975, 1977).
} 


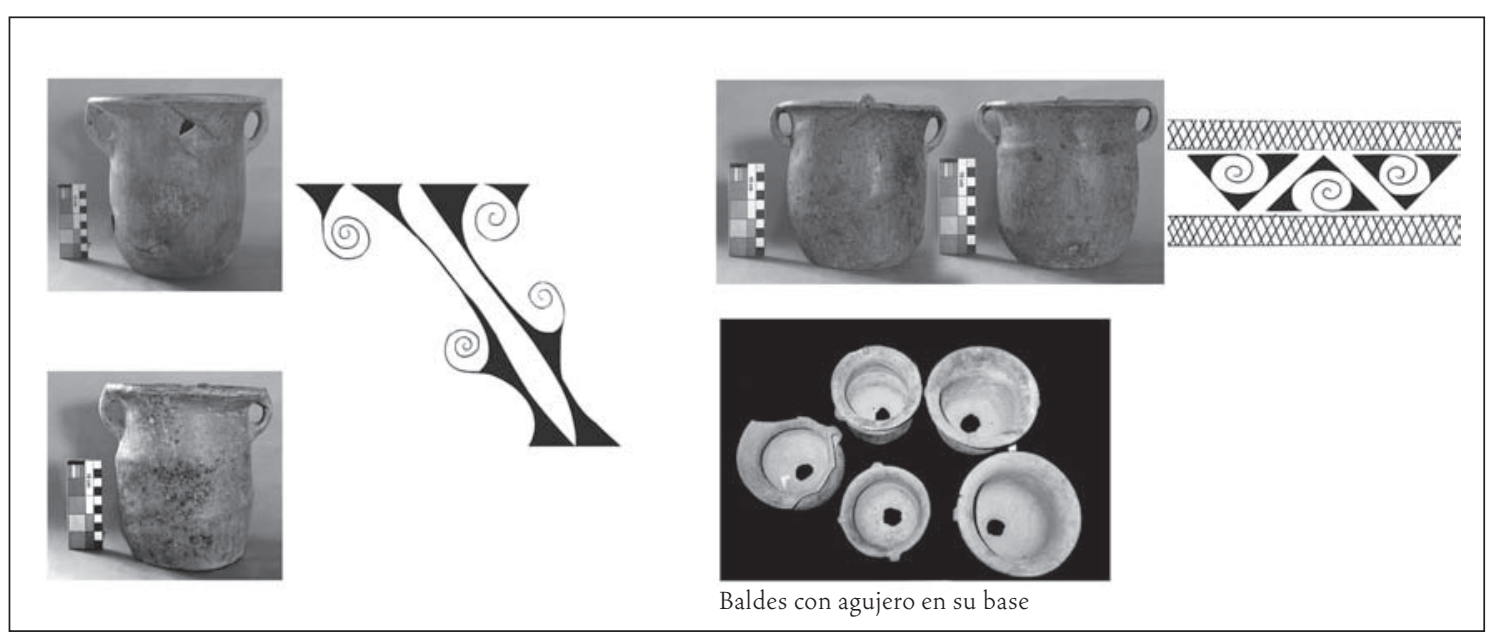

Figura 9. Piezas tipo “baldes" pertenecientes a la región de la Puna Nororiental.

halladas en sitios de la Puna Nororiental en gran cantidad, ya sea la base o ciertos tiestos diagnósticos (Krapovickas 1977; Krapovickas y Aleksandrowicz 1990) (Figura 10).

Un tercer caso son las características compositivas que presentan las botellas subglobulares con asas asimétricas (Figura 11). ${ }^{14}$ Su singularidad radica, principalmente entre las que poseen modelado antropomorfo, en contar con un diseño pictórico muy profuso con configuraciones de tipo reversible, en bandas irregulares o en friso, no sólo en su cuerpo, sino también en el modelado de su cuello, presentando pictografías en la cara y en los "gorros". Su diseño cromático exhibe combinaciones de gamas en negro desleído sobre rojo, negro desleído sobre morado y ante, rojo y ante. Estas botellas suelen ser pequeñas, estén en el contexto que estén, aunque quisiéramos resaltar un ejemplar relevado en el MEMÑ (pieza 108), el cual comparte la misma proporción y patrón morfológico que las botellas con asas asimétricas, pero sus dimensiones son 10 veces mayores (250 $\mathrm{mm}$ de diámetro máximo y $310 \mathrm{~mm}$ de altura). Esto nos lleva a pensar que muchas veces un patrón morfológico no se encuentra atado a su tamaño y que la

14 Recordemos que estas piezas se encuentran ampliamente distribuidas por lo menos en la Puna y en la Quebrada de Humahuaca (sitios Pucara de Tilcara, Huacalera, La Isla). percepción estilística puede estar acentuando otras variables de diseño.

Por último, nos detendremos en una pieza que llamó nuestra atención (MEMÑ 4 ). Se trata de una vasija de boca ancha con inclusiones de granos de cuarzo en su interior y de cestería en la base (ver Figura 10). La primera mención sobre estos ejemplares la realizó A. R. González (1963) para contextos de la Puna Occidental (específicamente de la región de Pozuelos). Años más tarde Krapovickas los asoció al tipo Pozuelos con Cuarzo de la alfarería yavi, dada la gran cantidad de hallazgos de tiestos de este tipo en contextos puneños (Krapovickas 1977; Krapovickas y Aleksandrowicz 1990). En realidad, estas piezas enseñan una amplia distribución en la Puna Occidental, Oriental, en las tierras bajas de los valles de Tarija (sitios Tomatitas y Pueblo Viejo de Tomatitas), valles de Santa Victoria, valles de San Andrés y Santa Cruz (sitio Antigüito) (Ventura 2001) y en la región de Sur Lípez (Nielsen com. pers. 2007). Estas piezas no comparten rasgos con ninguna otra y tienen una gran distribución. ¿Podemos hablar de alfarería de estilo yavi? ¿O son ejemplares que trascienden un único estilo, tratándose de un elemento compartido por distintas comunidades a lo largo del tiempo?

Quebrada de Humahuaca y Puna Occidental de Jujuy. Trasladándonos a contextos más alejados nos 


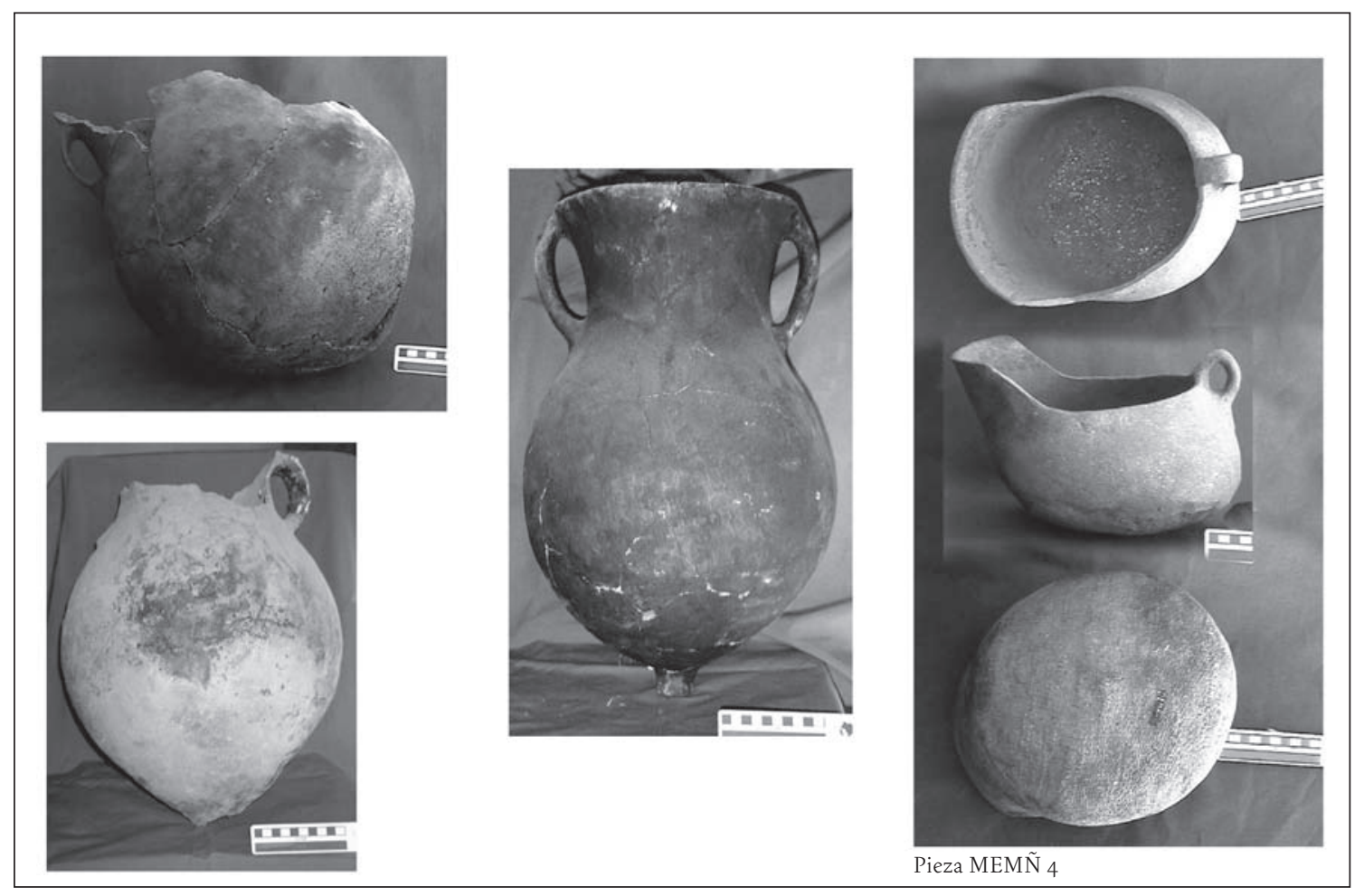

Figura 10. Piezas de grandes dimensiones pertenecientes a la región de la Puna Nororiental.

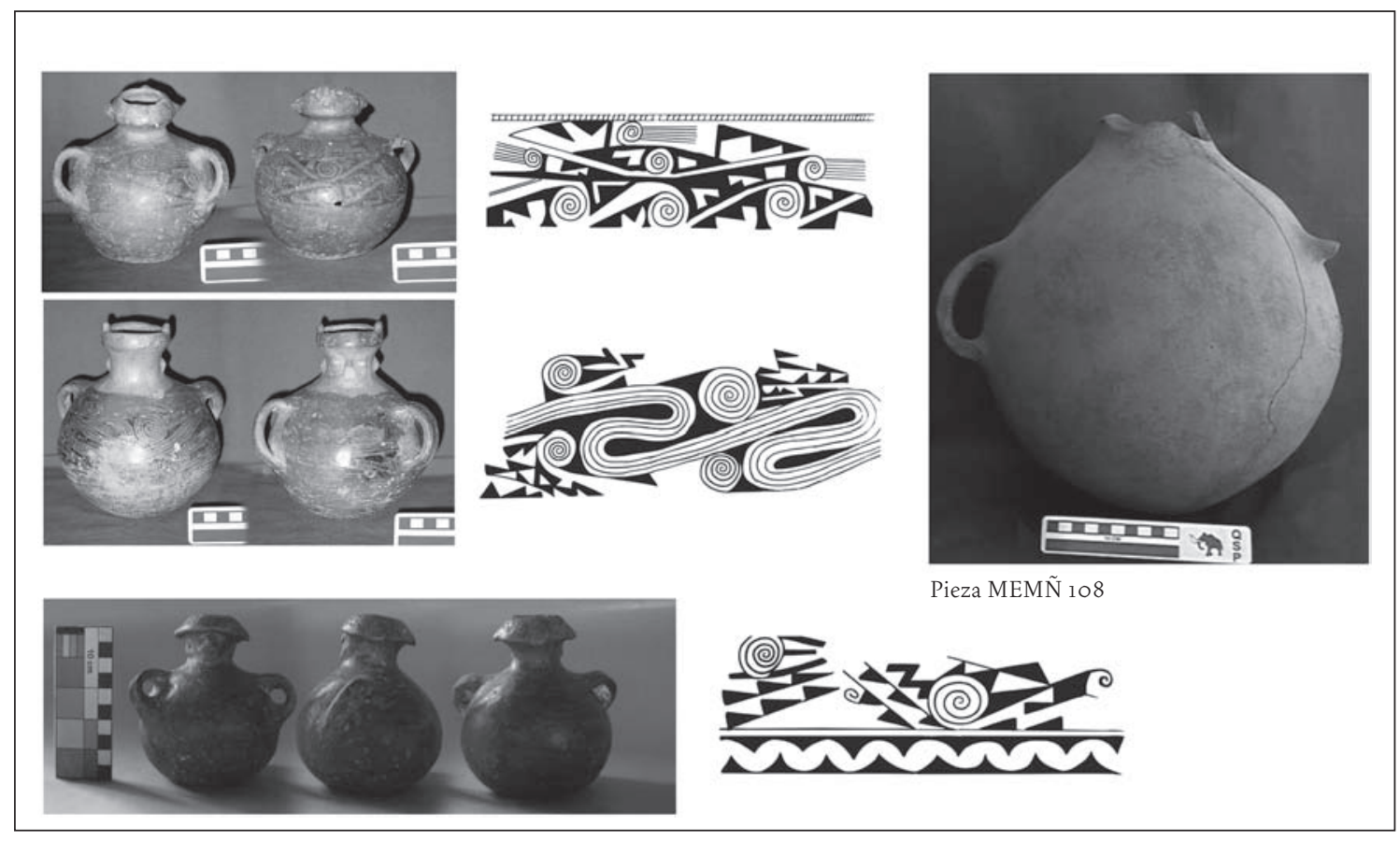

Figura 11. Botellas subglobulares con asas asimétricas pertenecientes a la región de la Puna Nororiental. 
preguntamos sobre la posible variación estilística de los ejemplares. En la Quebrada de Humahuaca las diferencias las observamos principalmente al detenernos en la composición pictórica: aquí el porcentaje es inverso al registrado en la Puna Nororiental, con el 64\% de los casos presentando configuraciones en friso, en zigzag angular, reversible, en bandas y reticular. En esta región se acentúa el porcentaje de piezas con diseño pictórico, la profusión de otras configuraciones (zigzag angular, reticular y en bandas) y la alta proporción de piezas policromas (Tabla 3). Por otro lado, no debemos olvidar las variaciones diacrónicas que observamos en este material, aún no pudiéndose contrastar con el registrado para la Puna Nororiental.

En el caso de la Puna Occidental, entre las piezas provenientes de las colecciones de los sitios Queta, Sorcuyo y Doncellas del IIT, se registraron cántaros compuestos bajos con composiciones morfológicas y de diseño muy similares a las registradas tanto para contextos quebradeños como puneños. También se encontraron "pelikes" con las mismas características que los observados para contextos quebradeños (Figura 12).Y, por último, se registró un cántaro con cuello engrosado (pieza IIT 1991) que merece una mención especial. Su morfología esta subsumida a un modelado antropomorfo, culminando en un rostro humano. Piezas similares no han sido registradas ni en la Puna Nororiental ni en contextos quebradeños. Ahora bien, dos ejemplares con características muy similares se observaron en el Museo Paleontológico y Arqueológico de Tarija (Bolivia). Comparten la composición cromática y pictórica de la anterior, aunque uno de ellos se encuentra subsumido a un modelado antropomorfo (seguramente femenino) y el otro tiene una estructura morfológica de tipo cántaro con cuello recto.

¿Qué trasciende las fronteras? La composición del diseño plástico de los ejemplares arriba mencionados, hallados en la Puna Occidental y en los valles de Tarija, dan la misma percepción compositiva que las piezas de estilo yavi, pero se encuentran ausentes en la Puna Nororiental. Es decir, fuera de la Puna Nororiental circulan piezas con el mismo diseño pictórico pero con composiciones y morfología diferentes. A su vez, piezas como los "baldes" sólo se encuentran en la Puna Nororiental y ejemplares de vasijas de boca ancha tipo pozuelos con cuarzo traspasan las fronteras de todas estas regiones. ¿Hay uniformidad en el material que circula? Las vías de tránsito son diferentes en cada contexto. Hay ejemplares que son iguales estén en el lugar que estén, hay otros que cambian radicalmente y otros en que lo que circulan son sólo algunas variables

\begin{tabular}{|c|c|c|c|c|c|c|}
\hline \multirow{2}{*}{$\begin{array}{l}\text { Subgrupo } \\
\text { estilístico }\end{array}$} & \multicolumn{3}{|c|}{ Morfología } & \multirow{2}{*}{$\begin{array}{c}\begin{array}{c}\text { Diseño } \\
\text { cromático }\end{array} \\
\text { Policromo }\end{array}$} & \multirow{2}{*}{$\begin{array}{c}\begin{array}{c}\text { Diseño } \\
\text { pictórico }\end{array} \\
\text { Presencia }\end{array}$} & \multirow{2}{*}{$\begin{array}{c}\text { Piezas } \\
\text { analizadas }\end{array}$} \\
\hline & Escudillas & Cántaros & Botellas & & & \\
\hline Yavi Temprano & $46 \%$ & $25 \%$ & $14 \%$ & $54 \%$ & $71 \%$ & 28 \\
\hline Yavi Tardío & $42 \%$ & $44 \%$ & $12 \%$ & $24 \%$ & $59 \%$ & 41 \\
\hline
\end{tabular}

Tabla 2. Comparación entre subgrupos estilísticos.

\begin{tabular}{|c|c|c|c|c|c|c|}
\hline \multirow{2}{*}{ Región } & \multicolumn{3}{|c|}{ Morfología } & $\begin{array}{c}\text { Diseño } \\
\text { cromático }\end{array}$ & $\begin{array}{c}\text { Diseño } \\
\text { pictórico }\end{array}$ & $\begin{array}{c}\text { Piezas } \\
\text { analizadas }\end{array}$ \\
\cline { 2 - 6 } & Escudillas & Cántaros & Botellas & Policromo & Presencia & \\
\hline $\begin{array}{c}\text { Puna } \\
\text { Nororiental }\end{array}$ & $40 \%$ & $37 \%$ & $19 \%$ & $27 \%$ & $34 \%$ & 93 \\
\hline $\begin{array}{c}\text { Quebrada de } \\
\text { Humahuaca }\end{array}$ & $43 \%$ & $36 \%$ & $13 \%$ & $36 \%$ & $64 \%$ & 63 \\
\hline
\end{tabular}

Tabla 3. Comparación entre regiones. 


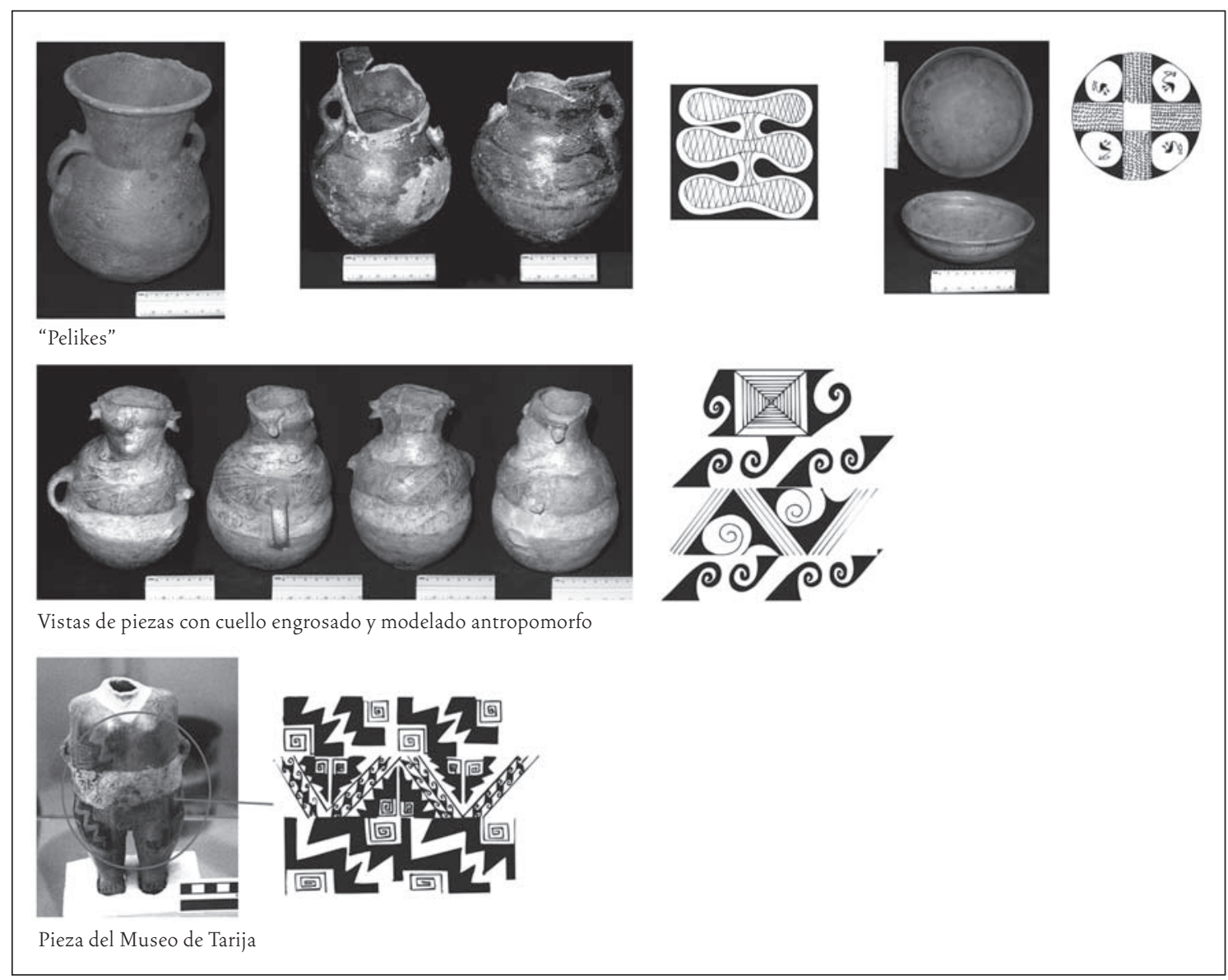

Figura 12. Piezas pertenecientes a la región de la Puna Occidental.

compositivas. El estilo no son sólo los objetos. Podemos observar el movimiento de objetos en sí (confeccionados localmente o transportados), de composiciones morfológicas, pictográficas o cromáticas, o elementos que son compartidos en más de un contexto.

\section{* Qué, CuÁndo y dónde. Reformulando PREGUNTAS}

Como hemos observado, los ítems que varían de un contexto a otro son distintos. Las diferencias se encuentran en piezas completamente nuevas, en variaciones en las combinaciones cromáticas, en las configuraciones pictóricas o en las variables morfológicas. Algunos ejemplos los observamos en las variaciones contextuales del diseño pictórico y cromático de las botellas subglobulares con asas asimétricas (distribuidas desde la región de Coquimbo en Chile hasta los valles de Tarija en Bolivia) o de las piezas tipo aribaloides (con diseños estilísticos Inka Paya en contextos quebradeños, atacameños y tarijeños). Otros en variaciones morfológicas, como el ejemplar MEMÑ 8, cuatro veces mayor que las botellas halladas en otros contextos. Y, por fin, en ejemplares que circulan diferencialmente, como los cántaros con base cónica y los "baldes" únicamente presentes en contextos puneños.

Entonces, ipodemos hablar de un estilo homogéneo, que se define en un territorio específico y hace circular ejemplares idénticos? El estilo no es un conjunto cerrado. Si bien hay una unidad compositiva que da cuenta de la identidad plástica, esta se encuentra lejos de constituir un paquete de rasgos. La composición plástica "is the most malleable and vulnerable to change 
through superficial contact" (Gosselain 2000: 190). El estilo, "material expression of ideas about roles, identities and relationships in the social world" (Costin y Wright 1998:3), se encuentra abierto a resignificaciones constantes, encontrándose históricamente condicionado y socialmente construido.

En este caso, ¿cuál es el contexto social en el que se enmarca? Pensando en sus antecedentes, el estilo alfarero yavi estuvo asociado a un sector específico del espacio, la Puna Nororiental de Jujuy y las serranías chichas en el sur de Bolivia. A su vez, se le dio el valor de "entidad cultural" capaz de identificar a un grupo étnico homogéneo, con un espacio territorial específico y un momento cronológico particular. Pero los procesos sociales que se sucedieron en esta región tuvieron gran dinamismo, alterando la composición de grupos y de unidades políticas estables. La movilidad nunca cesó. Desde los primeros tiempos hubo una intensa circulación de personas, objetos e ideas a ambos lados de los Andes. En tiempos del Tawantinsuyo la movilidad aumentó, producto de fragmentaciones, migraciones y reubicaciones poblacionales, voluntarias o forzadas, debido a políticas imperiales que produjeron el abandono y el establecimiento de nuevos poblados, así como seguramente la formación de espacios multiétnicos. Este continuo desplazamiento poblacional llegó a su cúspide con la conquista hispana en la que, a su vez, se produjeron abruptos decesos poblacionales. En este sentido, ipodemos relacionar a las poblaciones andinas con grupos homogéneos y de límites claros, tanto temporales como espaciales?

Si hablamos de sociedades con un alto grado de dinamismo, con movilizaciones, negociaciones y conflictos y de un estilo alfarero que varía de región en región y a lo largo del tiempo, ¿de qué forma podemos establecer una relación entre la alfarería y las características de los procesos sociales? Los materiales yavi no constituyen entidades inertes, sino componentes de una red y combinación de prácticas y relaciones. Y es en el accionar social en el que éstos representan, generan y forman las relaciones (Jones 2005), transformándose en parte constitutiva de las mismas (Warnier 2001).
Desde estas consideraciones, las diferencias plásticas pueden obedecer a distintas situaciones. Pueden ser producto de grupos sociales diferentes que realizan esta alfarería en sus propias comunidades (Angelo 1999) o revelar el traslado -forzado o voluntario-, de alfareros puneños a otros lugares llevando su propia alfarería o su tradición de confección (Williams y Cremonte 1992-93; Cremonte 1994; Cremonte y Solís 1998). O pueden resultar de la producción de alfarería en espacios multiétnicos, donde se cruzan distintos grupos con distintas tradiciones (Stovel 2002). Lo cierto es que la alfarería yavi comparte una unidad perceptiva que la identifica como tal, pero en cada lugar y situación en que entra en acción se pueden producir variaciones en su composición plástica.

Tomando la variable temporal, cabe pensar que los cambios estilísticos afectaron en alguna instancia el desarrollo de las relaciones sociales y las experiencias individuales. Con el correr del tiempo las manifestaciones plásticas cambian de configuración, de técnica, de motivos. Estas particularidades pudieron estar relacionadas a distintas prácticas, por ejemplo, a fundación de nuevas identidades o a cambios en el desarrollo de actividades sociales compartidas, como lo observamos para el siglo XIII en la Quebrada de Humahuaca.

Respecto a la variable espacial, ¿qué es lo que circula? ¿Son los objetos, son las representaciones, son los modos de representar? Lo que hemos observado es que hay una gran dispersión del estilo con mayor o menor frecuencia en todos los Andes circumpuneños, acrecentándose esta tendencia en momentos incaicos. A partir de esto icómo se puede interpretar la dinámica de las redes de relaciones entre las personas? El extenso y dispar esparcimiento puede deberse a diversas causas, como formas alternativas de circulación, ya sea de comercio o de intercambio, de objetos o de información; traslados de personas a distintos puntos; ideas compartidas o prácticas de citación de eventos o lugares:

"The social practices related to making, using and depositing material objects can be thought of as 'material citations', 
each material act references and gains its meaning from that which has gone before" (Jones 2005: 200).

Los cambios y continuidades temporales, la dispersión espacial, los contextos, la materialidad y la iconicidad de los objetos contribuyen activa y recursivamente a producir y reproducir la vida social, generando, muchas veces por su sola presencia, el desarrollo de ciertas prácticas.
Agradecimientos Este trabajo se desprende de mi Tesis de Licenciatura, la que se realizó gracias al gran apoyo de la gente y las instituciones que allí se mencionan. En lo que respecta a la presente versión, se agradecen los comentarios de los evaluadores, así como de mi director Dr. Axel Nielsen. Sin más, queda bajo mi responsabilidad lo aquí expuesto.

\section{$\diamond$ Referencias citadas}

AdÁn, L. y M. URiBe, 2005. El dominio inca en la localidad de Caspana: Un acercamiento al pensamiento político andino (río Loa, norte de Chile). Estudios Atacameños 29: 41-66.

Agüero, C., M. Uribe, P. Ayala y B. Cases, 1997. Variabilidad textil durante el período Intermedio Tardío en el valle de Quillagua: Una aproximación a la etnicidad. Estudios Atacameños 14:263-290.

Albeck, M. E., 2001. La Puna argentina en el período MedioTardío. En Historia argentina prehispánica, vol. ı. E. Berberián y A. Nielsen (Eds), pp. 347-388. Editorial Brujas, Córdoba.

Alliende, P., 1981. La colección arqueológica Emil de Bruyne de Caspana. Tesis para optar al Título de Arqueólogo. Universidad de Chile, Santiago.

Angelo, D., 1999. Tráfico de bienes, minería y aprovechamiento de recursos en la región de los valles del sur boliviano. Tesis de Licenciatura en Arqueología. Universidad Mayor de San Andrés, La Paz.

Arellano, L. J., 1984. La cultura Tarija: Aportes al conocimiento de los señoríos regionales del sur boliviano. Arqueología Boliviana 1: 73-81.

ÁviLA, F., 2005. El estilo alfarero yavi y su relación con la construcción de identidades culturales. Theoria 14 (1): 85-101.

2006. Un mundo morado sobre ante. Estudio del estilo cerámico yavi de la Puna Oriental de Jujuy. Tesis de Licenciatura en Ciencias Antropológicas con orientación arqueológica. Universidad de Buenos Aires, Buenos Aires.

2008. Un universo de formas, colores y pinturas. Caracterización del estilo alfarero yavi de la Puna Nororiental de Jujuy. Intersecciones en Antropología 9. En prensa.
Baldini, L. y M. Albeck, 1983. La presencia hispana en algunos cementerios del valle de Santa María, Catamarca. En Presencia hispánica en la arqueología argentina 2: 549-566.

Beaudry, M. C., L. J. Cook y A. Mrozowski, 1991. Artifacts and active voice: Material culture as social discourse. En The archaeology of inequality, R. McGuire y R. Paytner (Eds.), pp. 150-191. Blackwell Press, Oxford.

Berenguer, J., 2004. Caravanas, interacción y cambios en el Desierto de Atacama. Sirawi Ediciones, Santiago.

Bravo, L., 1991. Las evidencias puneñas en los oasis de San Pedro. Actas del XI Congreso Nacional de Arqueología Chilena (1988), vol. 2, pp. 115-120. Santiago.

Calderari, M., 1988. Estilos cerámicos incaicos de La Paya. Actas del XI Congreso Nacional de Arqueología Chilena (1988), vol. 2, pp. 151-163. Santiago.

Calderari, M. y V. Williams, 1991. Revaluación de los estilos cerámicos incaicos en el Noroeste Argentino. Comechingonia II (9): 75-95.

Cantarutti, G. y R. Mera, 2000 . Estadio Fiscal de Ovalle: Redescubrimiento de un sitio diaguita-inca en el valle del Limarí. Actas del XIV Congreso Nacional de Arqueología Chilena (1998), vol. 2, pp. 353-360. Arica.

2003 Ms. Alfarería de la fase Inca en el valle del Limarí: Evidencias de influencia Yavi o Chicha en jarros antropomorfos. Manuscrito en poder de los autores.

CONKey, M.y C. Hastorf (Eds.), 1990. The uses of style in archaeology. Cambridge University Press, Cambridge.

Costin, C. y C. Wright (Eds.), 1998. Craft and social identity. Archaeological Papers of the American Anthropological 
Association 8, American Anthropological Association, Arlington.

Coote, J.y A. Shelton, 1992. Anthropology, art and aesthetics. Oxford University Press, Oxford.

Cremonte, M. B., 1992. Algo más sobre el Pucara de Tilcara. Análisis de una muestra de superficie. Cuadernos 3:35-52.

1994. Tendencias en relación a la producción y distribución de la cerámica arqueológica de la Quebrada de Humahuaca. Actas del Taller "De costa a selva: Producción e intercambio entre los pueblos agroalfareros de los Andes Centro Sur" (1992), M. E. Albeck (Ed.), pp. 177-197. Instituto Interdisciplinario de Ticara, San Salvador de Jujuy.

2005. Aspectos económicos y políticos con respecto a la ocupación inca en los valles meridionales de Jujuy, Argentina. En Sociedades precolombinas surandinas: Temporalidad, interacción y dinámica cultural del NOA en el ámbito de los Andes Centro Sur, V. Williams, B. Ventura, A. Callegari y H. Yacobaccio (Eds.), pp. 109-125. Buenos Aires.

Cremonte, M. B. y N. Solís, 1998. La cerámica del Pucara de Volcán: Variaciones locales y evidencia de interacción. En Los desarrollos locales y sus territorios. Arqueología del NOA y sur de Bolivia, M. B. Cremonte (Ed.), pp. 155-196. Universidad Nacional de Jujuy, San Salvador de Jujuy.

Fernández, J., 1978. Los chichas, los lípez y un posible enclave de la cultura de San Pedro de Atacama en la Puna limítrofe argentino-boliviana. Estudios Atacameños 6:19-35.

Garay de Fumagalli, M., 1997. Diferenciación formal y cronológica de los yacimientos de la cuenca superior del río Corral de Piedra. Cuadernos 9: 71-85.

2003. Del Formativo al Incaico, los valles sur orientales de Jujuy en los procesos de interacción macrorregionales. En $L a$ mitad verde del mundo andino. Investigaciones arqueológicas en la vertiente oriental de los Andes y las tierras bajas de Bolivia y Argentina, B. Ventura y G. Ortiz (Eds.), pp. 229-260. Universidad Nacional de Jujuy, San Salvador de Jujuy.

Gell, A., 1998. Art and agency. An anthropological theory. Clarendon Press, Oxford.

GonzÁlez, A. R., 1963. Problemas arqueológicos de la Puna argentina. En A Pedro Bosch Gimpera en el septuagésimo aniversario de su nacimiento, pp. 58-72. Instituto Nacional de Antropología e Historia/Universidad Nacional Autónoma de México, México D. F.

González, L. y M. Tarragó, 2005. Vientos del sur. El valle de Yocavil (Noroeste Argentino) bajo la dominación incaica. Estudios Atacameños 29: 67-95.
González, P., 1995. Presencia altiplánica en el norte semiárido. El tipo Saxamar en los diseños cerámicos Diaguita III. Museos 19: 8-11.

Gosselain, O. P., 2000. Materializing identities: An African perspective. Journal of Archaeological Method and Theory 7 (3): $187-217$.

Ibarra Grasso, D. E., 1957. Nuevas culturas arqueológicas de los antiguos indígenas de Chuquisaca, Potosí y Tarija. En Arqueología boliviana, C. Ponce Sanginés (Ed.), pp. 32 1-339. Biblioteca Paceña-Alcaldía Municipal, La Paz.

Ibarra Grasso, D. E. y R. Querejazu, 1986.30000 años de prehistoria de Bolivia. Enciclopedia boliviana. Los Amigos del Libro, La Paz-Cochabamba.

Jones, A., 2005. Lives in fragments? Personhood and the European Neolithic. Journal of Social Archaeology 5 (2): 193-224.

KRAPOVICKAS, P., 1965. La cultura Yavi, una nueva entidad cultural puneña. Etnia 2: 9-10.

1973. Arqueología de Yavi Chico (provincia de Jujuy, República Argentina). Revista del Instituto de Antropología de la Ciudad de Córdoba IX: 5-22.

1975. Algunos tipos cerámicos de Yavi Chico. Actas y Trabajos del Primer Congreso de Arqueología Argentina (1960), pp. 293-300. Buenos Aires.

1977. Arqueología de Cerro Colorado (departamento de Yavi, provincia de Jujuy, República Argentina). En Obra del Centenario del Museo de La Plata, vol. 2, pp. 123-148. Museo de La Plata, La Plata.

1984. Relations between the Argentine Puna and its eastern border zone. Social and economics organizations in the prehispanic Andes. Actas del XLIV Congreso Internacional de Americanistas (1982). BAR Internacional Series 194, Oxford.

1994. Algunas observaciones respecto a los vínculos entre el noreste de la Puna argentina y las regiones colindantes. Síntesis. Actas del Taller "De costa a selva:Producción e intercambio entre los pueblos agroalfareros de los Andes Centro Sur" (1992), M. E. Albeck (Ed.), pp. 7-15. Instituto Interdisciplinario de Tilcara, San Salvador de Jujuy.

Krapovickas, P. y S. Aleksandrowicz, 1990. Breve visión de la cultura Yavi. Anales de Arqueología y Etnología XLI-XLII, pp. 83-127. Universidad Nacional de Cuyo, Mendoza.

LeChtman, H., 1977. Style in technology: Some early thoughts. En Material culture: Styles, organization and dynamics of technology, $\mathrm{H}$. Lechtman y R. S. Merrill (Eds.), pp.3-20. St. Paul, American Ethnological Society, Minnesota. 
LESURE, R., 2005. Linking theory and evidence in an archaeology of human agency: Iconography, style and theories of embodiment. Journal of Archaeological Method and Theory 12 (3): $237-255$.

Lorandi, A., M. B. Cremonte y V. Williams, 1991. Identificación étnica de los mitmakunas instalados en el establecimiento incaico de Potrero Chaquiago. Actas del XI Congreso Nacional de Arqueología Chilena (1988), vol. 2, pp. 195-200. Santiago.

Mamani, H., 1998. El paisaje arqueológico en el sector occidental de la cuenca de Pozuelos (Jujuy, Argentina). En Los desarrollos locales y sus territorios: Arqueología del NOA y sur de Bolivia, M. B. Cremonte (Ed.), pp. 257-283. Universidad Nacional de Jujuy, San Salvador de Jujuy.

Martínez, J. L., 1992. Acerca de las etnicidades de la Puna árida en el siglo XVI. En Etnicidad, economía y simbolismo en los Andes, S. Arze, R. Barragán, L. Escobari, X. Medinaceli (Eds.), pp. 35-65. Actas del II Congreso de Etnohistoria, Coroico. HISBOL-IFEA-SBU-ASUR, La Paz.

1995. Textos y palabras. Cuatro documentos del siglo XVI. En Espacio, etnias y fronteras. Atenuaciones politicas en el sur del Tawantisuyo siglos XV-XVIII, A. Presta (Ed.), pp. 45-71. ASUR, Sucre.

Nielsen, A., 1998. Tendencias de larga duración en la ocupación humana del Altiplano de Lípez (Potosí, Bolivia). En Los desarrollos locales y sus territorios. Arqueología del NOA y sur de Bolivia, M. B. Cremonte (Ed.), pp. 65-102. Universidad Nacional de Jujuy, San Salvador de Jujuy.

2001. Evolución social en Quebrada de Humahuaca (700-1536 DC). En Historia argentina prehispánica, vol. 1. E. Berberián y A. Nielsen (Eds.), pp. 171-264. Editorial Brujas, Córdoba.

2002. Asentamientos, conflictos y cambio social en el Altiplano de Lípez (Potosí, Bolivia). Revista Española de Antropología Americana 32: 179-202.

2003. Por las rutas del Zenta: Evidencias directas de tráfico prehispánico entre Humahuaca y las yungas. En La Mitad verde del mundo andino. Investigaciones arqueológicas en la vertiente oriental de los Andes y las tierras bajas de Bolivia y Argentina, B. Ventura y G. Ortiz (Eds.), pp. 261-284. Universidad Nacional de Jujuy, San Salvador de Jujuy.

2006. Pobres jefes: Aspectos corporativos en las formaciones sociales preincaicas de los Andes circumpuneños. En Contra la tiranía tipológica en arqueología: Una visión desde Sudamérica, C. Gnecco y C. Langebaek (Eds.), pp. 121-150. Universidad de los Andes-Ceso, Bogotá.
2007. El período de Desarrollos Regionales en la Quebrada de Humahuaca: Aspectos cronológicos. En Sociedades precolombinas surandinas: Temporalidad, interacción y dinámica cultural del NOA en el ámbito de los Andes Centro Sur, V. Williams, B. Ventura, A. Callegari y H. Yacobaccio (Eds.), pp. 235-251. Buenos Aires.

Nielsen, A., M. Vásquez, J. Ávalos y C. Angiorama, 2000. Prospecciones arqueológicas en la Reserva Eduardo Avaroa (Sud Lípez, depto. Potosí, Bolivia). Textos Antropológicos 11: 89-131.

Niemeyer, H., 1988. Excavación del Cementerio Alto del Carmen, provincia del Huasco. Boletín de la Sociedad Chilena de Arqueología 8: 2-4.

Palma, J., 1998. Curacas y señores: Una visión de la sociedad política prehispánica en la Quebrada de Humahuaca. Instituto Interdisciplinario Tilcara, San Salvador de Jujuy.

Pérez Gollán, J. A., 1973. Arqueología de las culturas agroalfareras de la Quebrada de Humahuaca (provincia de Jujuy, República Argentina).América Indígena XXXIII: 667-678.

Rafino, R. y J. Palma, 1993. Las ciudades inca en Argentina: Arqueología de La Huerta de Humahuaca. Los artefactos. En Inka. Arqueología, historia y urbanismo del altiplano andino, R. Raffino (Ed.), pp. 93-129. Corregidor, Buenos Aires.

Raffino, R., R. J. Alvis, D. Olivera y J. R. Palma, 1986. La instalación inca en la sección andina meridional de Bolivia y extremo boreal de Argentina. Comechingonia II (9): 63-131.

Rendón, P., 2004. Proyecto arqueológico Tarija-Saire. Una aproximación a la arqueología de Tarija: El sitio Saire, estudio de las singularidades de su cerámica y la relación de ésta con otros conjuntos. Tesis de Grado. Universidad Mayor de San Andrés, La Paz.

Rivera, C., 1998 Ms. Settlement patterns and regional interaction in the Cinti valley, Chuquisaca, Bolivia. Ponencia presentada en la $63^{\text {a }}$ Reunión de la Sociedad de Arqueología Americana, Seattle.

2003. Identidades compartidas en el sur de Bolivia: Interacciones entre las poblaciones prehispánicas del valle de Cinti y las tierras bajas del sureste. En La Mitad verde del mundo andino. Investigaciones arqueológicas en la vertiente oriental de los Andes y las tierras bajas de Bolivia y Argentina, B. Ventura y G. Ortiz (Eds.), pp. 179-203. Universidad Nacional de Jujuy, San Salvador de Jujuy.

2006. Complejidad social y esferas de interacción durante el Horizonte Medio y el período Intermedio Tardío en los valles 
interandinos del suroeste de Chuquisaca, Cinti. En Esferas de interacción prehistóricas y fronteras nacionales modernas: Los Andes sur centrales, H. Lechtman (Ed.), pp. 167-198. Instituto de Estudios Peruanos, Lima.

Rivolta, C., 2005. Cambio social en la Quebrada de Humahuaca en tiempos prehispánicos (1100-1400 DC). Instituto Interdisciplinario Tilcara, San Salvador de Jujuy.

RYDÉN, S., 1944. Contributions to the archaeology of the rí Loa region. Elanders Boktrykeri Aktiebolag, Göteborg.

Schiappacasse, V., V. Castro y H. Niemeyer, 1989. Los desarrollos regionales en el Norte Grande (1000-1400 DC). En Culturas de Chile. Prehistoria, J. Hidalgo, V. Schiappacasse y H. Niemeyer, C. Aldunate e I. Solimano (Eds.), pp. 181-220. Editorial Andrés Bello, Santiago.

Stovel, E., 2002. The importance of being Atacameño: Political identity and mortuary ceramics in Northern Chile. Tesis Doctoral. Graduate School of Binghamton University, State University of New York, Binghamton.

TARRAGÓ, M., 1968. Secuencias culturales de la etapa agroalfarera de San Pedro de Atacama (Chile).Actas y Memorias del XXXVII Congreso Internacional de Americanistas (1966), vol. 2, pp.119144. Buenos Aires.

1989. Contribución al conocimiento arqueológico de las poblaciones de los oasis de San Pedro de Atacama en relación con los otros pueblos puneños, en especial el sector septentrional del valle Calchaquí. Tesis para optar al Título de Doctor en Historia, Especialidad Antropología. Universidad Nacional de Rosario, Rosario.

Togo, J., 1973. Prospección arqueológica en el departamento Santa Victoria, provincia de Salta. Actualidad Antropológica, Suplemento de Etnía 12: 7-13.

Uribe, M., 1997. La alfarería de Caspana en relación a la prehistoria tardía de la subárea circumpuneña. Estudios Atacameños 14: $243-262$.
2002. Sobre alfarería, cementerios, fases y procesos en la prehistoria tardía del Desierto de Atacama. Estudios Atacameños 22: 7-31.

2004a. Alfarería, arqueología y metodología. Aportes y proyecciones de los estudios cerámicos del Norte Grande de Chile. Tesis para optar al Grado de Magíster en Arqueología. Universidad de Chile, Santiago.

2004b. El Inka y el poder como problemas de la arqueología del Norte Grande de Chile. Chungara, Revista de Antropología Chilena $36(2): 313-324$.

Uribe, M. y G. Cabello, 2005. Cerámica en el camino: Los materiales del río Loa (Norte Grande de Chile) y sus implicaciones tipológicas y conductuales para la comprensión de la vialidad y la expansión del Tawantinsuyo. Revista Española de Antropología Americana 35: 75-98.

Ventura, B., 2001. Los últimos mil años en la arqueología de las yungas. En Historia argentina prehispánica, vol. 1. E. Berberian y A. Nielsen (Eds.), pp. 447-492. Editorial Brujas, Córdoba.

Von Rosen, E., 1957. Un mundo que se va. Fundación Miguel Lillo, Universidad Nacional del Tucumán. Instituto Miguel Lillo, Opera Lilloana 1, San Miguel del Tucumán.

Warnier, J. P., 2001. A praxeological approach to subjectivation in a material world. Journal of Material Culture 6 (1): 5-24.

Wiessner, P., 1990. Is there a unity to style? En The uses of style in archaeology, M. Conkey y C. Hastorf (Eds.), pp. 105-113. Cambridge University Press, Cambridge.

Williams, V. y M. B. Cremonte, 1992-93. ¿Mitmaquna o circulación de bienes? Indicadores de la producción cerámica como identificadores étnicos. Un caso de estudio en el Noroeste Argentino. Avances en Arqueología 2: 9-21. 